Article

\title{
Aberrant DOCK2, GRASP, HIF3A and PKFP Hypermethylation has Potential as a Prognostic Biomarker for Prostate Cancer
}

\author{
Marianne T. Bjerre ${ }^{1,2}$, Siri H. Strand ${ }^{1}$, Maibritt Nørgaard ${ }^{1}$, Helle Kristensen ${ }^{3}$, \\ Anne KI Rasmussen ${ }^{3}$, Martin Mørck Mortensen ${ }^{2}$, Jacob Fredsøe ${ }^{1} @$, Peter Mouritzen ${ }^{3}$, \\ Benedicte Ulhøi ${ }^{4}$, Torben Ørntoft ${ }^{1}$, Michael Borre ${ }^{2}$ and Karina D. Sørensen ${ }^{1, *}$ (D) \\ 1 Department of Molecular Medicine (MOMA), Aarhus University Hospital (AUH), \\ Palle Juul-Jensens Boulevard 99, 8200 Aarhus N, Denmark; mtbjerre@clin.au.dk (M.T.B.); \\ siri.strand@clin.au.dk (S.H.S.); mno@clin.au.dk (M.N.); jcf@clin.au.dk (J.F.); orntoft@clin.au.dk (T.Ø.) \\ 2 Department of Urology, Aarhus University Hospital (AUH), Palle Juul-Jensens Boulevard 99, 8200 Aarhus N, \\ Denmark; Martin.Moerck.Mortensen@vest.rm.dk (M.M.M.); borre@clin.au.dk (M.B.) \\ 3 Exiqon - a Qiagen company, Skelstedet 16, 2950 Vedbæk, Denmark; vejsehelle@hotmail.com (H.K.); \\ anne.karin.rasmussen@gmail.com (A.K.R.); mouritzenpeter0@gmail.com (P.M.) \\ 4 Department of Pathology, Aarhus University Hospital (AUH), Palle Juul-Jensens Boulevard 99, \\ 8200 Aarhus N, Denmark; beneulho@rm.dk \\ * Correspondence: kdso@clin.au.dk; Tel.: +45-78455316
}

Received: 13 December 2018; Accepted: 28 February 2019; Published: 7 March 2019

check for updates

\begin{abstract}
Prostate cancer (PCa) is a clinically heterogeneous disease and currently, accurate diagnostic and prognostic molecular biomarkers are lacking. This study aimed to identify novel DNA hypermethylation markers for PCa with future potential for blood-based testing. Accordingly, to search for genes specifically hypermethylated in PCa tissue samples and not in blood cells or other cancer tissue types, we performed a systematic analysis of genome-wide DNA methylation data (Infinium 450K array) available in the Marmal-aid database for 4072 malignant/normal tissue samples of various types. We identified eight top candidate markers (cg12799885, DOCK2, FBXO30, GRASP, HIF3A, MOB3B, PFKP, and TPM4) that were specifically hypermethylated in PCa tissue samples and hypomethylated in other benign and malignant tissue types, including in peripheral blood cells. Potential as diagnostic and prognostic biomarkers was further assessed by the quantitative methylation specific PCR (qMSP) analysis of 37 nonmalignant and 197 PCa tissue samples from an independent population. Here, all eight hypermethylated candidates showed high sensitivity (75-94\%) and specificity (84-100\%) for PCa. Furthermore, DOCK2, GRASP, HIF3A and PKFP hypermethylation was significantly associated with biochemical recurrence (BCR) after radical prostatectomy (RP; 197 patients), independent of the routine clinicopathological variables. DOCK2 is the most promising single candidate marker (hazard ratio (HR) $(95 \%$ confidence interval (CI)): 1.96 (1.24-3.10), adjusted $p=0.016$; multivariate cox regression). Further validation studies are warranted and should investigate the potential value of these hypermethylation candidate markers for blood-based testing also.
\end{abstract}

Keywords: DNA methylation; prostate cancer; epigenetics; biomarker; diagnosis; prognosis

\section{Introduction}

Prostate cancer (PCa) is the fourth most commonly diagnosed malignancy in the world and is the most prevalent cancer among men [1,2]. Suspicion of PCa is typically raised by an elevated serum prostate specific antigen (PSA) test and/or an abnormal digital rectal examination (DRE). This is 
generally followed by ten to twelve trans-rectal ultrasound-guided (TRUS) prostate biopsies, which are histologically evaluated for presence of PCa [3]. However, the PSA test is prostate- rather than PCa-specific, and up to $75 \%$ of initial TRUS-biopsy procedures are negative [4]. Conversely, up to $25 \%$ of clinically significant prostate cancers are missed at the initial TRUS-biopsy [5], together leading to many repeat biopsies and delayed detection of potentially aggressive PCa. Early intervention is crucial to prevent potentially aggressive PCa from metastatic progression, which is associated with high mortality [6], however, the majority of newly diagnosed early stage prostate cancers are clinically insignificant and do not benefit from immediate treatment. Indeed, localized PCa can be cured by radical prostatectomy (RP), while low-risk localized PCa may be safely monitored by active surveillance (AS) [7]. Currently, initial treatment choice is based exclusively on clinical variables (mainly PSA, clinical T-stage (cT), and the biopsy Gleason Score (GS) [8]), but these are suboptimal, leading to the overtreatment of many clinically insignificant prostate cancers as well as the delayed/suboptimal treatment of aggressive prostate cancers $[9,10]$. Hence, there is a strong clinical need for better diagnostic and prognostic biomarkers for PCa. Ideally, such novel biomarkers should be highly PCa-specific and suitable for a minimally invasive testing, e.g., in blood samples.

PCa is characterized by a relatively small mutational load in the early stages of the disease [11], whereas epigenetic changes in the DNA methylome occur frequently and consistently [12]. Hypermethylation of promoter-associated CpG islands has been closely linked with the silencing of tumor suppressor genes [13] and has shown promising diagnostic and prognostic biomarker potential for PCa in tissue-based studies [14-17], although translation into blood-based tests has been slow. Indeed, most previous studies aimed at developing blood-based DNA methylation markers for PCa have not assessed if a given candidate marker was hypermethylated in other (non-prostate) tissue types also or in peripheral blood cells [18], which could increase the risk of false positive signals in cell-free DNA (cfDNA) in blood (plasma/serum).

In the present study, we aimed to identify novel PCa-specific DNA methylation candidate markers with potential for future blood-based testing by also taking into account DNA methylation levels in other tissue types. To this end, we used a systematic discovery approach based on a very large Infinium HumanMethylation450 (450K) array dataset from the Marmal-aid database [19]. Marmal-aid contains genome-wide DNA methylome data (450K) from over 14,000 samples, representing 22 different normal/malignant human tissue types (prostate, bladder, colorectal, lung, kidney, prostate and several other organs) and more than 50 distinct cell types (e.g., several leukocyte subtypes). We discovered and validated eight candidate markers: DOCK2 (dedicator of cytokinesis 2), cg12799885 (intergenic), FBXO30 (F-box protein 30), GRASP (general receptor for the phosphoinositides 1-associated scaffold protein), HIF3A (hypoxia inducible factor 3 subunit alpha), MOB3B (MOB kinase activator 3B), PFKP (phosphofructokinase, platelet), and TPM4 (tropomyosin 4). These markers were hypermethylated in PCa tissue samples and hypomethylated in normal prostate tissue, other normal and cancer tissues and in peripheral blood cells (PBC), suggesting promising diagnostic potential for PCa. Four of the candidates (DOCK2, GRASP, HIF3A and PKFP) also showed significant prognostic potential beyond routine clinicopathological parameters for the prediction of post-operative biochemical recurrence in a cohort of 197 patients who underwent radical prostatectomy.

\section{Results}

\subsection{Large-Scale Bioinformatics Analysis for the Discovery of PCa-Specific Candidate DNA Methylation Markers}

In order to identify novel diagnostic and prognostic biomarker candidates for PCa, we used the Illumina 450K methylation datasets from the Marmal-aid database [19]. Out of 14,486 human tissue samples with the 450K data available in the Marmal-aid database, we initially excluded 9809 samples that were not from men, 73 samples that failed quality control and 632 samples of unknown or ambiguous disease status (Figure 1). The remaining 4047 samples, all derived from men and of known tissue type and disease status, were used for further bioinformatics analysis (Table S1). Thus, 
the final discovery set included $450 \mathrm{~K}$ methylome data from 81 normal prostate and $187 \mathrm{PCa}$ tissue samples, 634 normal and 2294 cancer samples from other tissue types than prostate and 876 peripheral blood cell (PBC) samples (Figure 1, Table S1). The rational for also including non-prostate sample types in the discovery phase is that we aimed to identify genes specifically hypermethylated in PCa tissue samples and not in blood cells or other cancer tissue types, increasing the likelihood that these candidate markers would also be suitable for future blood-based testing for PCa.

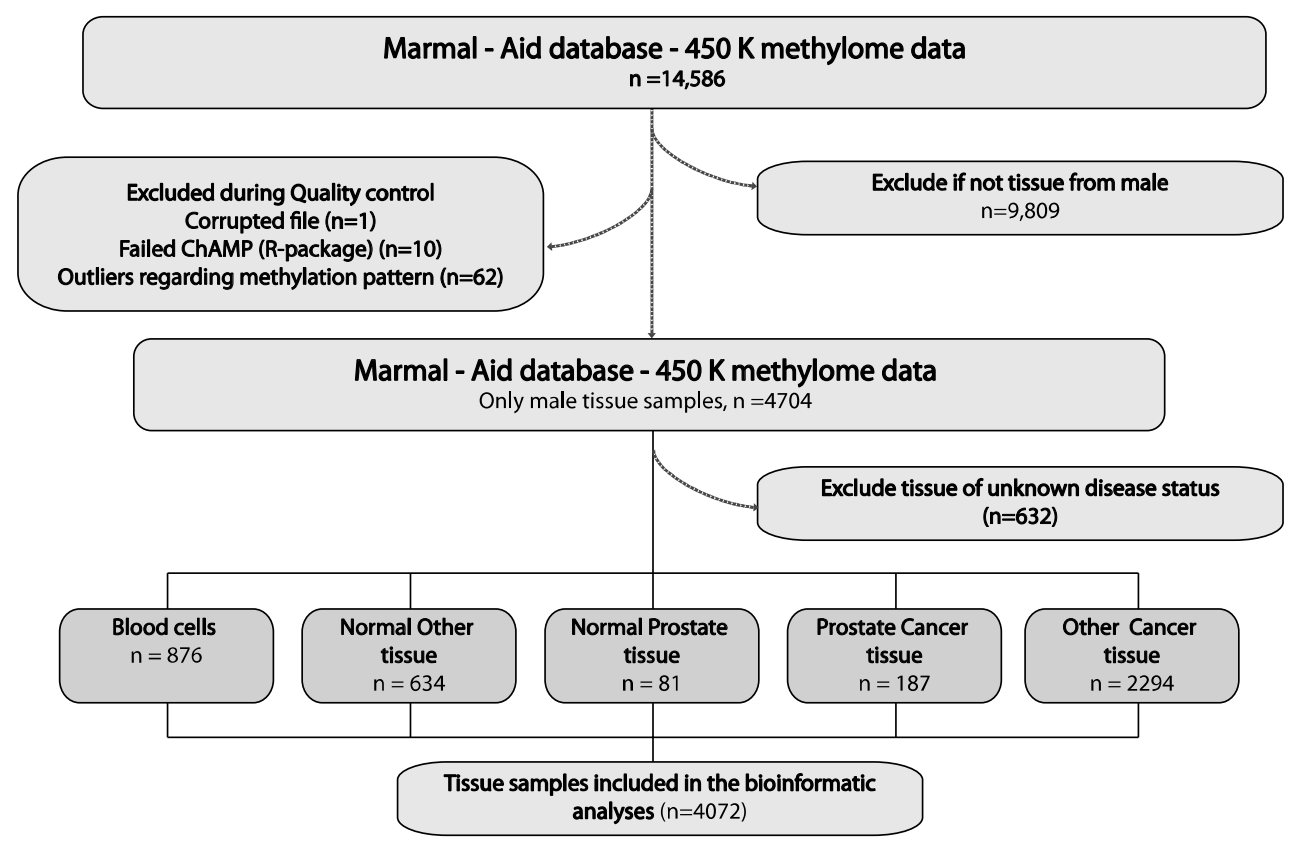

Figure 1. Selection of samples and biomarker candidates. Tissue sample selection for bioinformatics analyses. We selected male samples $(n=4072)$ with known disease status to ensure specificity for prostate cancer $(\mathrm{PCa})$ versus other cancers and non-malignant tissues.

To minimize the future risk of false positive signals in plasma, caused by methylated cfDNA derived from PBCs, we initially filtered out all of the CpG sites $(n=410,901$ out of 485,513 CpG sites interrogated on the $450 \mathrm{~K}$ array) that showed detectable levels of methylation $(B>0.2)$ in more than $1 \%$ of the 876 PBC samples analyzed (Figure 2). Next, we used a two-stringed biomarker discovery approach based on the remaining 74,612 CpG sites (Figure 2, further details on the candidate marker selection criteria are given in Section 4.1).

The first approach (Figure 2, left) was the least stringent and was simply aimed to identify DNA methylation marker candidates that distinguished PCa from healthy prostate tissue samples, but not necessarily distinguishing PCa from other cancer types. Although such "pan-cancer" markers may not be useful for PCa screening in plasma due to risk of false positive signals from other malignancies, they could potentially improve specificity for PCa in men with elevated PSA. After the exclusion of 73,408 CpG sites that were hypomethylated in PCa tissue samples ( $B<0.5$ in $>20 \%$ of PCa samples), as well as $1119 \mathrm{CpG}$ sites that were hypermethylated in normal prostate tissue samples $(B>0.2$ in $>19 \%$ of samples), we identified five top candidate hypermethylation markers for PCa (Figure 2). Four of these (DOCK2, HIF3A, GRASP and PFKP) were selected for further validation, as they had a high CpG density (not shown) and hence were suitable for the design of quantitative methylation specific PCR (qMSP) assays (see Section 2.2). 


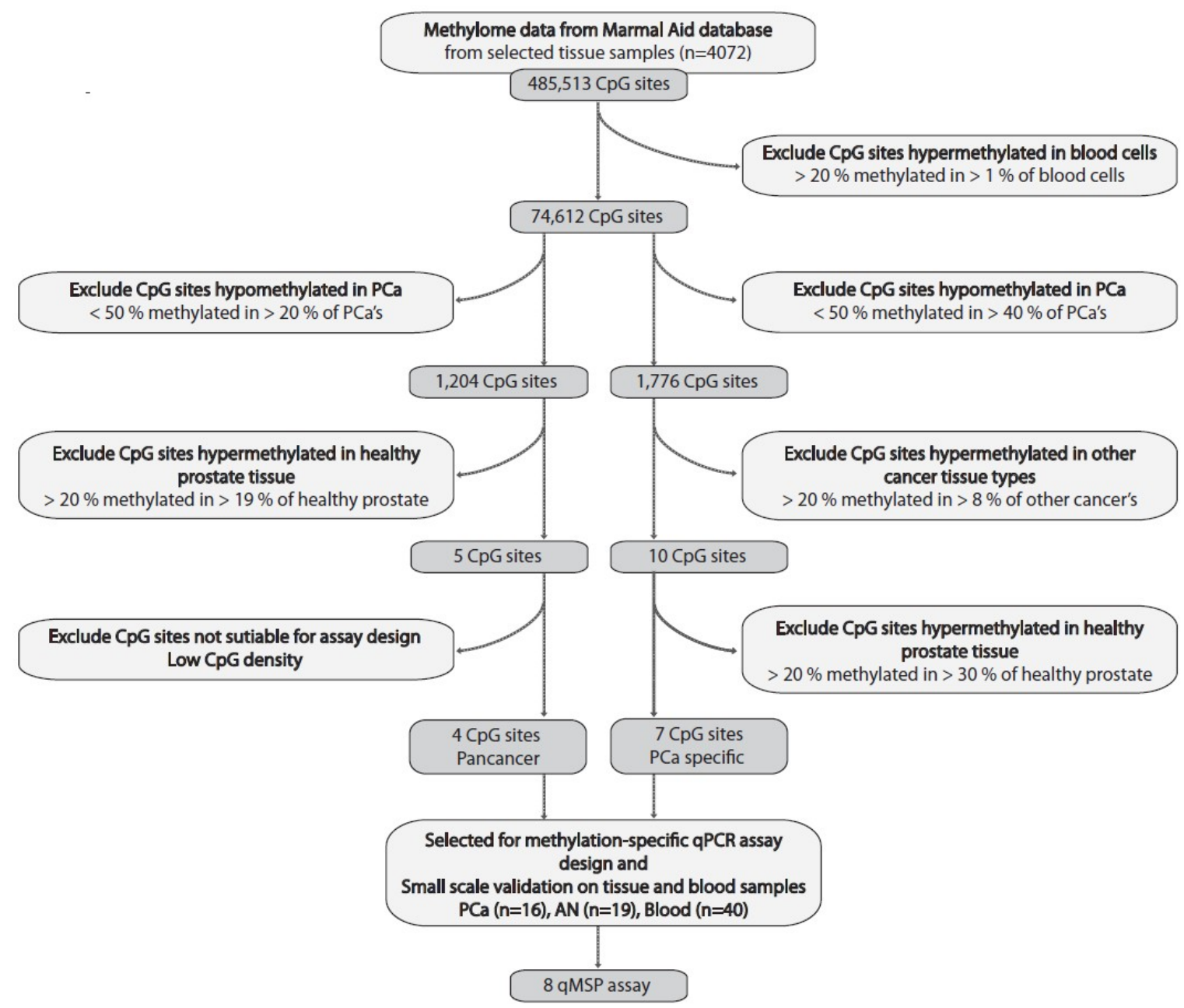

Figure 2. Flow chart of biomarker discovery process using $450 \mathrm{~K}$ array data from the Marmal-aid database. Bioinformatics analyses: To identify CPG sites that may also be suitable for a future blood-based testing, we initially excluded CpG sites that displayed signs of methylation in blood cells ( $n=876$ samples). Next, we used a 2-stringed discovery approach to identify: 1$)$ "Pan-cancer" biomarker candidates; we selected CpG sites with hypermethylation in PCa tissue samples and excluded CpG sites with hypermethylation in normal prostate tissue. 2) PCa-specific biomarker candidates; we selected CpG sites with hypermethylation in PCa tissue samples and excluded CpG sites with hypermethylation in other cancer types and/or in normal prostate tissue samples. This resulted in the selection of four "pan-cancer" and seven "PCa-specific" CpG sites suitable for the qMSP assay design.

Our second approach (Figure 2, right) was more stringent and aimed to identify "truly" PCa-specific hypermethylation candidate markers, which were hypomethylated in normal prostate tissue ( $B \leq 0.2$ in $\geq 70 \%$ of samples) as well as and in other types of cancer tissue samples ( $B \leq 0.2$ in $\geq 92 \%$ of samples). We excluded $72,836 \mathrm{CpG}$ sites that were hypomethylated in $\mathrm{PCa}(\mathrm{B}<0.5 \mathrm{in}>40 \%$ of samples) and 1,766 CpG sites that were hypermethylated in other cancer tissue types, as well as 3 CpG sites that were hypermethylated in normal prostate tissue samples (Figure 2). This approach identified seven candidate PCa-specific hypermethylation markers (cg12799885, C2orf43, C2orf88, FBXO30-cg23095615, FBXO30-cg09094393, MOB3B and TPM4), all of which were suitable for the qMSP assay design and were selected for further validation (see Section 2.2 below). Of note, these candidates were also hypomethylated in other normal non-prostate tissue samples (Figure 3). 

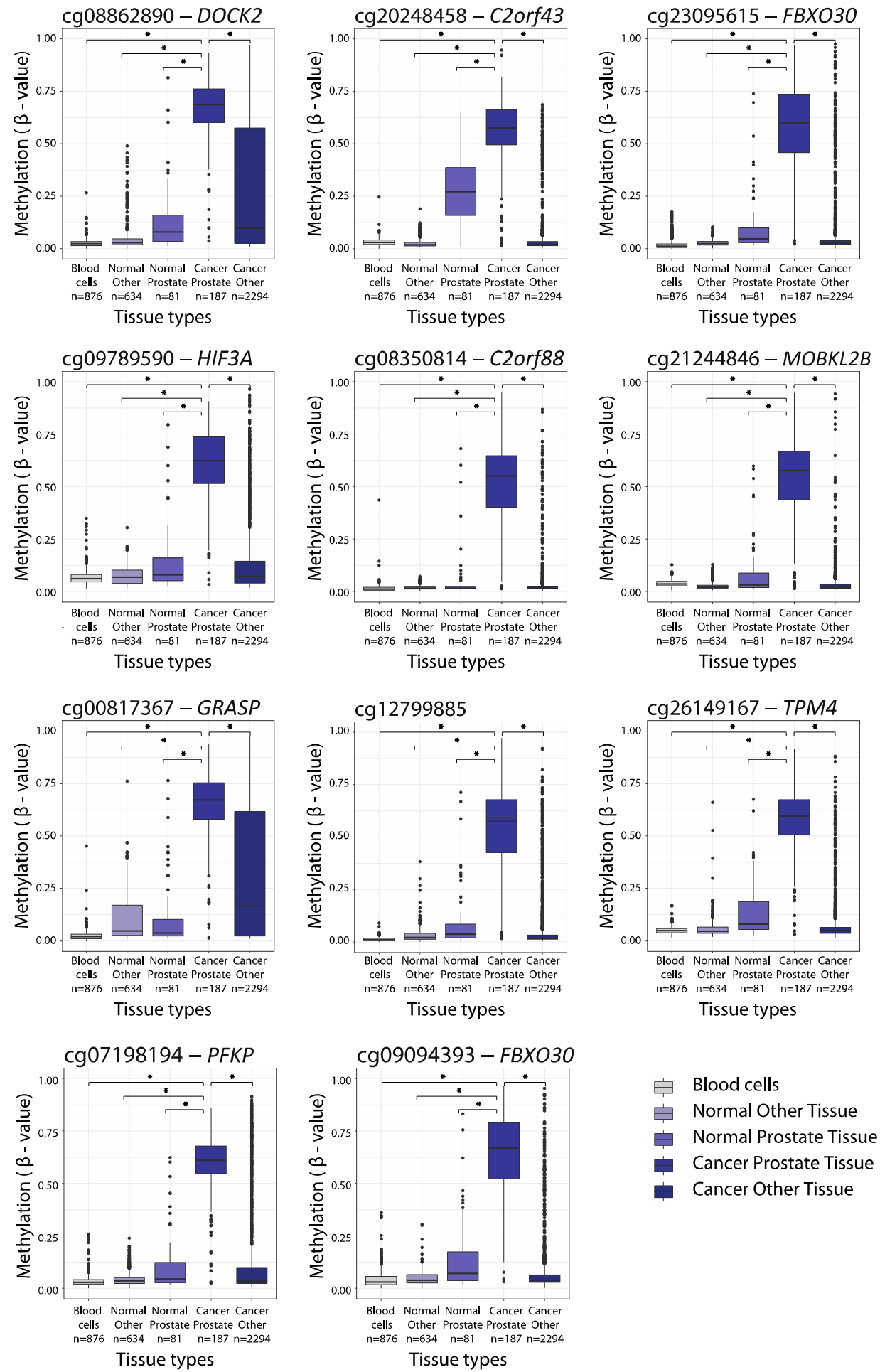

Figure 3. Methylation levels (ß-values) for the 11 selected biomarker candidates in the blood cell samples $(n=876)$, normal prostate tissue samples $(n=81)$, other normal tissue samples $(n=634)$, prostate cancer tissue samples $(n=187)$ and other cancer tissue samples $(n=2294)$. Other normal/cancer sample types included 14 different groups (AML (acute myeloid leukemia)/ALL (acute lymphoblastic leukemia), bladder, CNS (central nervous system), colorectal, head and neck, liver, lung, lymphoma, kidney, melanoma, pancreatic, sarcoma, stomach and thyroid). ${ }^{*} p<0.001$ (Wilcoxon Mann-Whitney test). The colored boxes indicate the 25-75th percentiles and the black horizontal lines indicate the median. Top whiskers are the 3 rd quartile +1.5 interquartile range and the bottom whiskers are the 1 st quartile -1.5 interquartile range. Round dots indicate outliers. 
In total, using 450K data from Marmal-aid, we identified 11 candidate markers (CpG sites) that were essentially unmethylated (median $B<0.06)$ in PBC samples $(n=876)$, while at the same time being significantly hypermethylated in PCa tissue $(n=187)$ when compared to normal prostate tissue samples $(n=81)$ and compared to 14 other normal/malignant tissue types $(n=634 / n=2294)$ (median $B$ difference $>0.30 ; p<0.001$, Mann-Whitney test; Figure 3). For all of the $11 \mathrm{CpG}$ sites, the median methylation level ( $\$$-value) was $>0.55$ in the PCa samples, and $<0.27$ in the non-malignant prostate specimens and $<0.07 /<0.17$ for the other normal/malignant tissue types (Figure 3). Further details on the methylation levels for each candidate marker in individual cancer types are given in Supplementary Figure S1.

\subsection{Independent Experimental Validation of Top Candidate Hypermethylation Markers}

Next, we performed a small-scale experimental validation through the qMSP analysis of an independent set of 19 adjacent normal (AN) and 16 PCa tissue samples, as well as 40 blood (PBC) samples from male donors (Figure S2). Out of the 11 biomarker candidates analyzed, eight (cg12799885, DOCK2, FBXO30-cg23095615, GRASP, HIF3A, MOB3B, PFKP and TPM4) were selected for further large-scale validation (Section 2.3), as each of these showed high sensitivity (75-94\%) and high specificity (84-100\%) for PCa compared to AN and, furthermore, were undetectable in the PBC samples ( $0 \%$ false positive rate) (Table S2).

\subsection{Large-Scale Validation of Diagnostic Potential}

In order to further validate the diagnostic potential of our eight selected DNA methylation marker candidates, we carried out qMSP analyses on a larger patient sample set, counting in total 197 PCa samples, 28 AN samples and 9 benign prostatic hyperplasia (BPH) tissue samples (Table 1). For all eight candidates, the PCa samples were significantly hypermethylated as compared to the non-malignant prostate tissue samples (AN/BPH) $(p<0.001$, Mann-Whitney test; Supplementary Figure S3). By receiver operating characteristics (ROC) curve analysis, the corresponding areas under the curve (AUC) ranged from 0.85 (FBXO30) to 0.95 (GRASP) (Figure 4). Furthermore, when fixing specificity at $95 \%$, the sensitivity for PCa ranged from 71\% (FBXO30) to $96 \%$ (GRASP) (Supplementary Table S3). Thus, all eight methylation biomarker candidates (cg12799885, DOCK2, FBXO30, GRASP, HIF3A, MOB3B, PFKP and TPM4) displayed promising diagnostic potential for PCa. Moreover, in The Cancer Genome Atlas (TCGA) PCa patient dataset ( $n=532$ with RNAseq and 450K data available), we found a significant inverse correlation between transcriptional gene expression and the DNA methylation levels for DOCK2, FBXO30, GRASP, HIF3A, MOB3B, PFKP and TPM4 $(p<0.001$; rho: 0.33-0.64; Supplementary Figure S4). Furthermore, except for DOCK2, all of the genes were significantly downregulated in PCa $(n=497)$ compared to the AN $(n=35)$ tissue samples in the TCGA set $(p \leq 0.001$, Wilcoxon Mann-Whitney test, Supplementary Figure S4), consistent with hypermethylation-based epigenetic gene silencing. cg12799885 is not clearly linked to a candidate gene and hence was not included in this part of the analysis.

Table 1. Clinicopathological characteristics of radical prostatectomy (RP) patient cohort and controls.

\begin{tabular}{cc}
\hline RP Cohort & PCa \\
\hline $\mathrm{N}$ & 197 \\
Age years, median (range) & $64(49-77)$ \\
\hline Preoperative PSA & \\
\hline PSA ng/mL, median (range) & $12.9(2.1-61.0)$ \\
\hline D'Amico Risk classification & \\
\hline Low risk, N (\%) & $23(11.7)$ \\
Intermediate risk, N (\%) & $80(40.6)$ \\
High risk, N (\%) & $91(46.2)$ \\
Unknown, N (\%) & $3(1.5)$ \\
\hline
\end{tabular}


Table 1. Cont

\begin{tabular}{cc}
\hline RP Cohort & PCa \\
\hline Pathological Gleason score & \\
\hline$<7, \mathrm{~N}(\%)$ & $63(32.0)$ \\
$>7, \mathrm{~N}(\%)$ & $98(49.7)$ \\
\hline N $(\%)$ & $36(18.3)$ \\
\hline Pathological T-stage & \\
\hline$<\mathrm{pT} 2 \mathrm{c}, \mathrm{N}(\%)$ & $42(21.3)$ \\
$=\mathrm{pT} 2 \mathrm{c}, \mathrm{N}(\%)$ & $85(43.1)$ \\
$>$ pT2c, N (\%) & $70(35.5)$ \\
\hline Surgical margin status & \\
\hline Negative, N (\%) & $137(69.5)$ \\
Positive, N (\%) & $60(30.5)$ \\
\hline Lymph node status & $5(2.5)$ \\
\hline Positive N1, N (\%) & $164(83.2)$ \\
Negative N0, N (\%) & $28(14.2)$ \\
\hline Unknown NX, N (\%) & $128(7-219)$ \\
\hline Follow-up & $107(54)$ \\
\hline Follow-up months, median (range) & BPH \\
PSA recurrence, N (\%) & 9 \\
\hline Controls & $70(57-81)$ \\
\hline N & AN \\
\hline Age years, median (range) & 28 \\
\hline
\end{tabular}

AN: Adjacent normal. BPH: Benign prostatic hyperplasia. PCa: Prostate cancer. PSA: Prostate specific antigen.

cg12799885

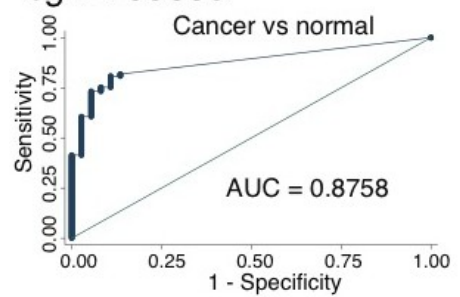

GRASP

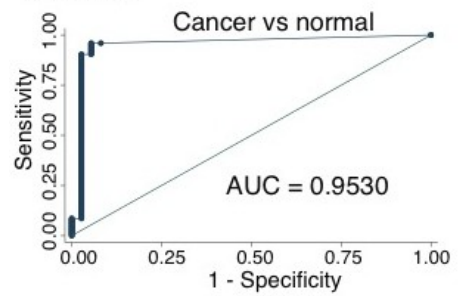

PFKP

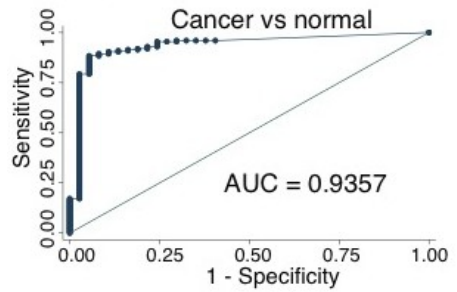

DOCK2

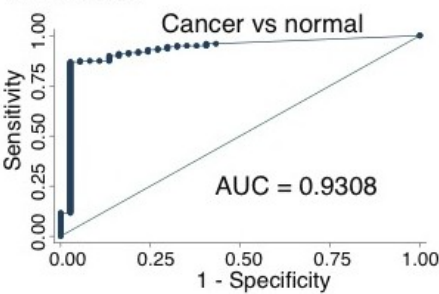

HIF3A

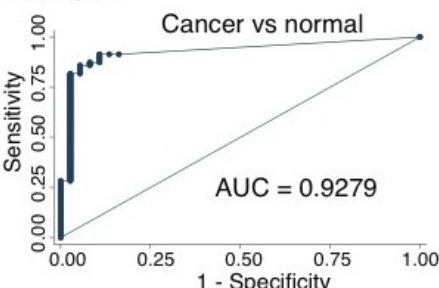

TPM4

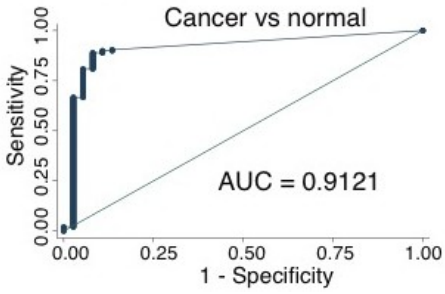

FBXO30

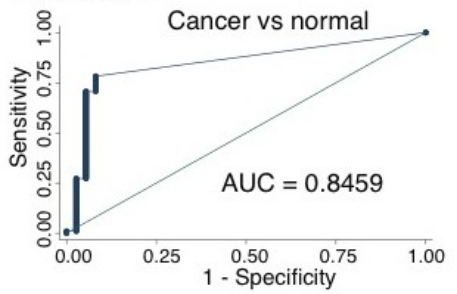

МОВ3В

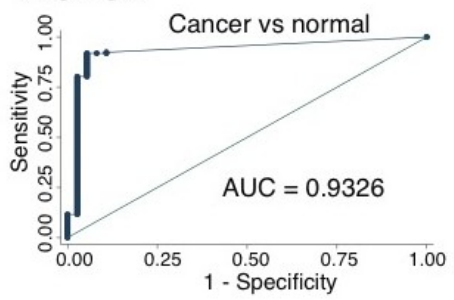

Figure 4. Diagnostic potential of selected methylation biomarker candidates. Receiver operating characteristics (ROC) curve analysis of the radical prostatectomy (RP) tissue samples $(n=197)$ as compared to the nonmalignant prostate tissue samples (28 AN and $9 \mathrm{BPH}$ ). AUC: Area under the curve. 


\subsection{Association Between DNA Methylation Levels in PCa Tumors and Clinicopathological Variables}

Next, we investigated the association between the DNA methylation levels of the eight biomarker candidates in PCa tissue samples and routinely used clinicopathological variables associated with tumor aggressiveness. We used the CAPRA-S score, which is a validated risk nomogram for biochemical recurrence (BCR) based on post-surgical clinicopathological variables and where a high score reflects adverse prognostic factors (high preoperative PSA, high prostatectomy GS, advanced pathological tumor stage (pT), positive surgical margin (SM) and/or positive lymph node involvement) [20]. For six of the candidates (cg12799885, DOCK2, GRASP, HIF3A, PFKP and TPM4), there was a significant correlation between high methylation levels and a high CAPRA-S score $(p<0.05$, Wilcoxon Mann-Whitney test; Figure 5), suggesting that higher methylation levels are linked with more aggressive PCa. Consistent with this, a high methylation level was significantly associated with post-operative BCR (compared to no BCR) for the four candidates DOCK2, GRASP, HIF3A, and PFKP (adjusted $p \leq 0.035$, Wilcoxon Mann-Whitney test.

\section{CAPRA-S score}
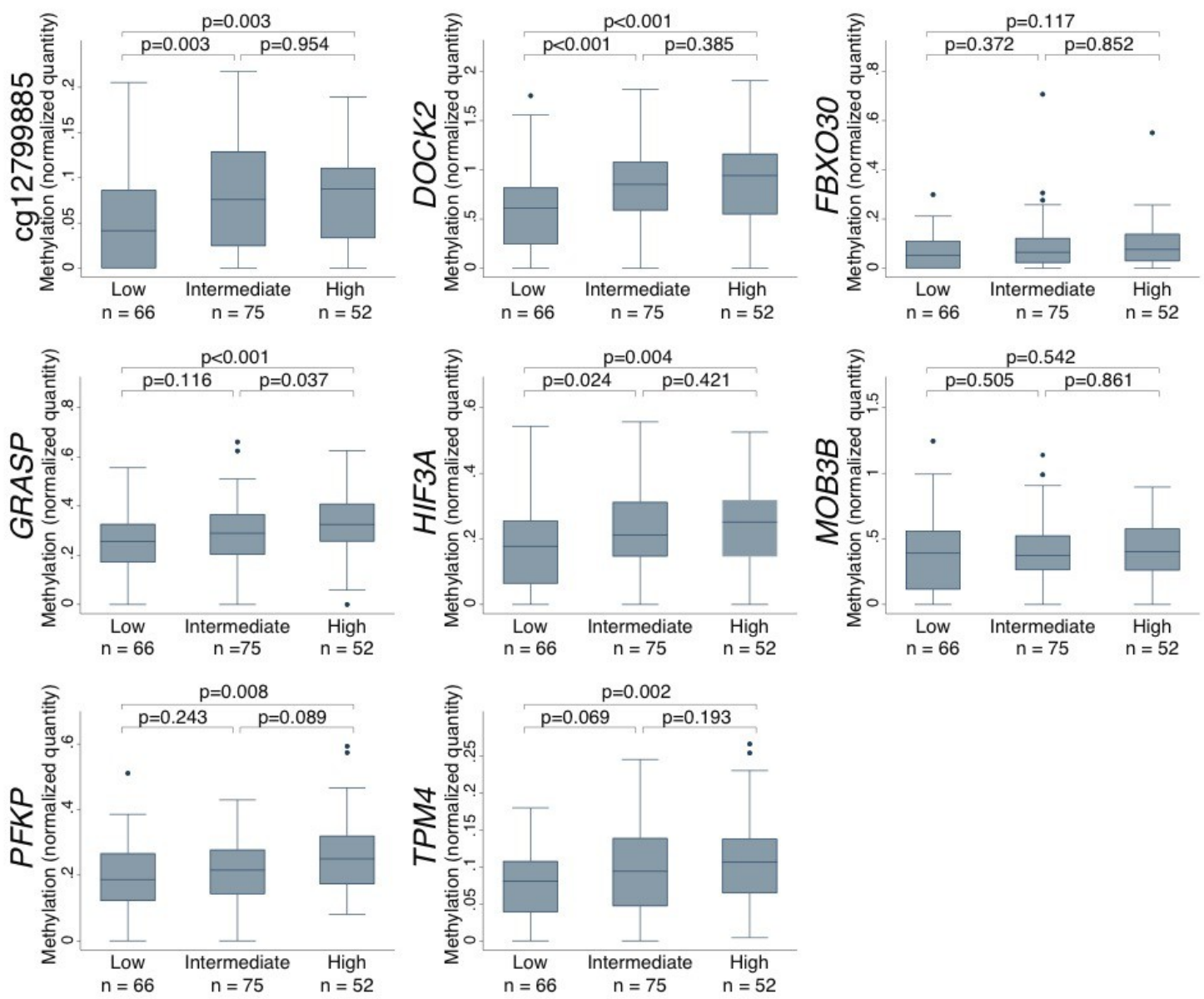

Figure 5. Box plots show the DNA methylation levels (normalized to ALUC4) for each top candidate marker as compared to the CAPRA-S risk score. CAPRA-S scores ranged from 0-2 (low), 3-5 (intermediate) and $\geq 6$ (high). $p$-value, Wilcoxon Mann-Whitney test. The colored boxes indicate the $25-75$ th percentiles and the black lines indicate the median. The top whiskers are the 3rd quartile +1.5 interquartile range and the bottom whiskers are the 1st quartile-1.5 interquartile range. Dots indicate outliers. 


\subsection{Prognostic Potential in Relation to Post-Operative Biochemical Recurrence Risk}

To further evaluate the prognostic potential of our eight biomarker candidates, we used univariate Cox regression analysis to investigate whether the methylation levels could predict the time to $B C R$ after RP. Hypermethylation of DOCK2, GRASP, HIF3A and PFKP (each analyzed as a continuous variable) were all significant predictors of time to $B C R$ after adjustment for multiple testing (Hochberg adjusted, $p<0.025$, Table 2). Of these four candidates, DOCK2 was the strongest single predictor of time to BCR after RP (HR (95\%): 2.50 (1.59-3.94), adjusted $p=0.001$; Table 2) in our RP cohort. All routine prognostic clinicopathological parameters (preoperative PSA, SM status, pathological GS (pGS) and pT-stage) were also significant predictors of time to BCR in the univariate Cox regression analysis $(p<0.026$, Table 2$)$, indicating that this is a representative RP cohort.

Table 2. Univariate Cox regression analysis using biochemical recurrence (BCR) after RP as endpoint. The Danish RP cohort included 234 patients in total. The methylation biomarker candidates were analyzed as continuous variables.

\begin{tabular}{|c|c|c|c|c|}
\hline \multirow[t]{2}{*}{ Variable } & \multicolumn{2}{|c|}{ Univariate Cox Regression } & \multirow[b]{2}{*}{ Adjusted $p$-value } & \multirow[b]{2}{*}{ C-Index } \\
\hline & HR $(95 \%$ CI) & $p$-value & & \\
\hline cg12799885 & $34.73(1.57-769.04)$ & $0.025^{*}$ & 0.100 & 0.570 \\
\hline DOCK2 & $2.50(1.59-3.94)$ & $<0.001^{*}$ & $0.001^{*}$ & 0.615 \\
\hline FBXO30 & $7.52(0.78-72.42)$ & 0.081 & 0.162 & 0.528 \\
\hline GRASP & $13.87(3.16-60.80)$ & $<0.001^{*}$ & $0.003^{*}$ & 0.606 \\
\hline HIF3A & $6.46(1.77-23.56)$ & $0.005^{*}$ & $0.024^{*}$ & 0.587 \\
\hline$M O B K L 2 B$ & $1.22(0.59-2.52)$ & 0.599 & 0.599 & 0.510 \\
\hline PFKP & $14.63(2.95-72.50)$ & $0.001^{*}$ & $0.006^{*}$ & 0.598 \\
\hline TPM4 & $40.03(1.21-1317.12)$ & $0.038^{*}$ & 0.114 & 0.547 \\
\hline $\begin{array}{c}\text { Surgical margin } \\
\text { (negative vs. positive) }\end{array}$ & $3.24(2.20-4.76)$ & $<0.001^{*}$ & $<0.001^{*}$ & 0.635 \\
\hline $\begin{array}{l}\text { Pre-op PSA dichotomized } \\
\qquad(<10 \text { vs } \geq 10)\end{array}$ & $1.99(1.25-3.15)$ & $0.004^{*}$ & $0.004^{*}$ & 0.572 \\
\hline $\begin{array}{l}\text { Pathological GS } \\
\text { (6-7 vs. } 8-10)\end{array}$ & $2.33(1.51-3.59)$ & $<0.001^{*}$ & $<0.001^{*}$ & 0.56 \\
\hline $\begin{array}{c}\text { Pathological T-stage } \\
\text { (pT2a-T2b vs. pT2c-pT4) }\end{array}$ & $1.80(1.07-3.03)$ & $0.026^{*}$ & $0.026^{*}$ & 0.552 \\
\hline Pathological N-stage & $2.83(1.13-7.04)$ & $0.026^{*}$ & $0.026^{*}$ & 0.514 \\
\hline Age at diagnosis & $0.96(0.93-1.00)$ & 0.054 & 0.054 & 0.554 \\
\hline
\end{tabular}

GS: Gleason score. Pre-op: Preoperative. HR: Hazard ratio. Adjusted $p$-value (Hochberg corrected). C-index (Harrell's C-index). * Significant $p$-values $(<0.05)$.

Likewise, by Kaplan-Meier analysis, we found that the median BCR-free survival time was significantly longer for patients with low methylation levels compared to those with high methylation level for each of the four candidates: DOCK2 (101 versus 37 months, adjusted $p=0.001$, log-rank test), HIF3A (>180 months versus 62 months; adjusted $p=0.012)$, GRASP (>178 months versus 65 months, adjusted $p=0.019$ ) and PFKP (103 months versus 51 months; adjusted $p=0.034$ ) (Figure 6).

Furthermore, all four candidates remained significant predictors of time to BCR after adjustment for routine clinicopathological factors in the multivariate Cox regression analysis: DOCK2 (HR (95\% CI): 1.96 (1.24-3.10), adjusted $p=0.016)$, HIF3A (HR (95\% CI): 4.73 (1.19-18.78), adjusted $p$ $=0.037)$, GRASP (HR (95\% CI); 5.24 (1.11-24.88), adjusted $p=0.037)$, and PFKP (HR (95\% CI)); 6.65 (1.23-36.12)) adjusted $p=0.037$ ) (Table 3). Thus, the hypermethylation of DOCK2, GRASP, HIF3A and $P F K P$, respectively, are significant independent predictors of time with $B C R$ after $R P$, even beyond routine clinicopathological variables.

Next, to find the optimal single/multi-marker panel, we performed stepwise backward selection using multivariate Cox regression analysis based on DOCK2, GRASP, HIF3A and PFKP and the routine clinicopathological factors preoperative PSA, surgical margin status (SM), pGS, and pT-stage. The final multivariate prognostic model consisted of DOCK2 together with the preoperative PSA, pGS and SM 
status (Table S4). The addition of DOCK2 to the multivariate model consisting of clinicopathological factors only improved the predictive accuracy (Harrell's C-index) from 0.692 to 0.710 (Table 3 and Table S4), suggesting improved model performance and indicating particularly promising prognostic potential for DOCK2 hypermethylation.

Table 3. Multivariate Cox regression analysis with biochemical recurrence (BCR) as an endpoint. The Danish RP cohort included 234 patients in total.

\begin{tabular}{|c|c|c|c|c|c|c|c|}
\hline \multirow[t]{2}{*}{ Variable } & \multicolumn{2}{|c|}{ Multivariate Cox Regression } & \multicolumn{5}{|c|}{ Final Multivariate Cox Regression } \\
\hline & $\begin{array}{c}\mathrm{HR} \\
(95 \% \mathrm{CI})\end{array}$ & $p$-value & $\begin{array}{c}\mathrm{HR} \\
(95 \% \mathrm{CI})\end{array}$ & $p$-value & $\begin{array}{c}\text { Adj } \\
p \text {-value }\end{array}$ & C-index ${ }^{a}$ & C-index ${ }^{b}$ \\
\hline DOCK2-continuous & $\begin{array}{c}1.95 \\
(1.20-3.17)\end{array}$ & $0.004^{*}$ & $\begin{array}{c}1.96 \\
(1.24-3.10)\end{array}$ & $0.004^{*}$ & $0.016^{*}$ & & - \\
\hline $\begin{array}{c}\text { Surgical margin } \\
\text { (negative vs. positive) }\end{array}$ & $\begin{array}{c}2.48 \\
(1.60-3.84)\end{array}$ & $<0.001^{*}$ & $\begin{array}{c}2.53 \\
(1.70-3.75)\end{array}$ & $<0.001^{*}$ & $<0.001^{*}$ & $0.719^{\mathrm{a}}$ & $0.692^{\mathrm{b}}$ \\
\hline $\begin{array}{l}\text { Preoperative PSA } \\
\quad(<10 \text { vs } \geq 10)\end{array}$ & $\begin{array}{c}1.82 \\
(1.14-2.90)\end{array}$ & $0.012^{*}$ & $\begin{array}{c}1.82 \\
(1.14-2.89)\end{array}$ & $0.012^{*}$ & $0.012^{*}$ & & $0.692^{\circ}$ \\
\hline $\begin{array}{l}\text { Path. Gleason score } \\
\quad(6-7 \text { vs. } 8-10)\end{array}$ & $\begin{array}{c}1.69 \\
(1.09-2.64)\end{array}$ & $0.020^{*}$ & $\begin{array}{c}1.69 \\
(1.09-2.64)\end{array}$ & $0.019^{*}$ & $0.019^{*}$ & & \\
\hline $\begin{array}{c}\text { Path. T-stage (pT2a-T2b } \\
\text { vs. pT2c-pT4) }\end{array}$ & $\begin{array}{c}0.96 \\
(0.54-1.70)\end{array}$ & 0.880 & - & - & - & - & - \\
\hline \multirow[t]{2}{*}{ Variable } & Multivariate & Regression & \multicolumn{5}{|c|}{ Final Multivariate Cox Regression } \\
\hline & $\begin{array}{c}\mathrm{HR} \\
(95 \% \mathrm{CI})\end{array}$ & $p$-value & $\begin{array}{c}\mathrm{HR} \\
(95 \% \mathrm{CI})\end{array}$ & $p$-value & $\begin{array}{c}\text { Adj } \\
p \text {-value }\end{array}$ & C-index ${ }^{a}$ & C-index ${ }^{b}$ \\
\hline HIF3A-continuous & $\begin{array}{c}4.73 \\
(1.14-19.5)\end{array}$ & $0.032^{*}$ & $\begin{array}{c}4.73 \\
(1.19-18.78)\end{array}$ & $0.027^{*}$ & $0.037^{*}$ & & - \\
\hline $\begin{array}{c}\text { Surgical margin } \\
\text { (negative vs. positive) }\end{array}$ & $\begin{array}{c}2.58 \\
(1.67-3.99)\end{array}$ & $<0.001^{*}$ & $\begin{array}{c}2.69 \\
(1.81-3.98)\end{array}$ & $<0.001^{*}$ & $<0.001^{*}$ & $0.713^{\mathrm{a}}$ & $0.692^{\mathrm{b}}$ \\
\hline $\begin{array}{l}\text { Preoperative PSA } \\
(<10 \text { vs } \geq 10)\end{array}$ & $\begin{array}{c}1.82 \\
(1.14-2.90)\end{array}$ & $0.012^{*}$ & $\begin{array}{c}1.83 \\
(1.15-2.92)\end{array}$ & $0.011^{*}$ & $0.011^{*}$ & & \\
\hline $\begin{array}{l}\text { Path. Gleason score } \\
\text { (6-7 vs. } 8-10)\end{array}$ & $\begin{array}{c}1.69 \\
(1.08-2.65)\end{array}$ & $0.022^{*}$ & $\begin{array}{c}1.70 \\
(1.09-2.66)\end{array}$ & $0.019^{*}$ & $0.019^{*}$ & & \\
\hline $\begin{array}{l}\text { Path. T-stage (pT2a-T2b } \\
\text { vs. pT2c-pT4) }\end{array}$ & $\begin{array}{c}0.99 \\
(0.56-1.76)\end{array}$ & 0.979 & - & - & - & - & - \\
\hline \multirow[t]{2}{*}{ Variable } & Multivariate & Regression & \multicolumn{5}{|c|}{ Final Multivariate Cox Regression } \\
\hline & $\begin{array}{c}\mathrm{HR} \\
(95 \% \mathrm{CI})\end{array}$ & $p$-value & $\begin{array}{c}\mathrm{HR} \\
(95 \% \mathrm{CI})\end{array}$ & $p$-value & $\begin{array}{c}\text { Adj } \\
p \text {-value }\end{array}$ & C-index ${ }^{a}$ & C-index ${ }^{b}$ \\
\hline GRASP-continuous & $\begin{array}{c}5.21 \\
(1.04-26.0)\end{array}$ & $0.044^{*}$ & $\begin{array}{c}5.24 \\
(1.11-24.9)\end{array}$ & $0.037^{*}$ & $0.037^{*}$ & & - \\
\hline $\begin{array}{c}\text { Surgical margin } \\
\text { (negative vs. positive) }\end{array}$ & $\begin{array}{c}2.39 \\
(1.54-3.71)\end{array}$ & $<0.001^{*}$ & $\begin{array}{c}2.53 \\
(1.69-3.77)\end{array}$ & $<0.001^{*}$ & $<0.001^{*}$ & $0.708^{a}$ & $0.692^{\mathrm{b}}$ \\
\hline $\begin{array}{l}\text { Preoperative PSA } \\
(<10 \mathrm{vs} \geq 10)\end{array}$ & $\begin{array}{c}1.75 \\
(1.10-2.78)\end{array}$ & $0.019^{*}$ & $\begin{array}{c}1.74 \\
(1.10-2.77)\end{array}$ & $0.019^{*}$ & $0.019^{*}$ & & \\
\hline $\begin{array}{l}\text { Path. Gleason score } \\
\text { (6-7 vs. } 8-10)\end{array}$ & $\begin{array}{c}1.70 \\
(1.09-2.67)\end{array}$ & $0.018^{*}$ & $\begin{array}{c}1.71 \\
(1.10-2.67)\end{array}$ & $0.017^{*}$ & $0.017^{*}$ & & \\
\hline $\begin{array}{c}\text { Path T-stage (pT2a-T2b } \\
\text { vs. pT2c-pT4) }\end{array}$ & $\begin{array}{c}1.03 \\
(0.58-1.81)\end{array}$ & 0.931 & - & - & - & - & - \\
\hline \multirow[t]{2}{*}{ Variable } & Multivariate & Regression & \multicolumn{5}{|c|}{ Final Multivariate Cox Regression } \\
\hline & $\begin{array}{c}\mathrm{HR} \\
(95 \% \mathrm{CI})\end{array}$ & $p$-value & $\begin{array}{c}\mathrm{HR} \\
(95 \% \mathrm{CI})\end{array}$ & $p$-value & $\begin{array}{c}\text { Adj } \\
p \text {-value }\end{array}$ & C-index ${ }^{a}$ & C-index ${ }^{b}$ \\
\hline PFKP-continuous & $\begin{array}{c}7.47 \\
(1.27-43.9)\end{array}$ & $0.026^{*}$ & $\begin{array}{c}6.65 \\
(1.23-36.1)\end{array}$ & $0.028^{*}$ & $0.037^{*}$ & & - \\
\hline $\begin{array}{c}\text { Surgical margin } \\
\text { (negative vs. positive) }\end{array}$ & $\begin{array}{c}2.44 \\
(1.58-3.79)\end{array}$ & $<0.001^{*}$ & $\begin{array}{c}2.60 \\
(1.75-3.86)\end{array}$ & $<0.001^{*}$ & $<0.001^{*}$ & $0.710^{\mathrm{a}}$ & $0.692^{\mathrm{b}}$ \\
\hline $\begin{array}{l}\text { Preoperative PSA } \\
\quad(<10 \text { vs } \geq 10)\end{array}$ & $\begin{array}{c}1.84 \\
(1.15-2.96)\end{array}$ & $0.012^{*}$ & $\begin{array}{c}1.85 \\
(1.16-2.97)\end{array}$ & $0.010^{*}$ & $0.010^{*}$ & & \\
\hline $\begin{array}{l}\text { Path.Gleason score } \\
\text { (6-7 vs. } 8-10)\end{array}$ & $\begin{array}{c}1.62 \\
(1.03-2.56)\end{array}$ & $0.033^{*}$ & $\begin{array}{c}1.65 \\
(1.05-2.59)\end{array}$ & $0.030^{*}$ & $0.030^{*}$ & & \\
\hline $\begin{array}{c}\text { Path. T-stage (pT2a-T2b } \\
\text { vs. pT2c-pT4) }\end{array}$ & $\begin{array}{c}1.01 \\
(0.57-1.79)\end{array}$ & 0.977 & - & - & - & - & - \\
\hline
\end{tabular}

Path.: Pathological. HR: Hazard ratio. Adj $p$-value: Hochberg corrected $p$-value. C-index ${ }^{\text {a }}$ : Harrell's C-index for the model including all variables significant in the multivariate analyses. C-index ${ }^{\mathrm{b}}$ : Harrell's C-index for the model only including the clinicopathological variables significant in multivariate analyses. * Significant $p$-values $(<0.05)$. - Not applicable. 


\section{Kaplan-Meier survival estimates}

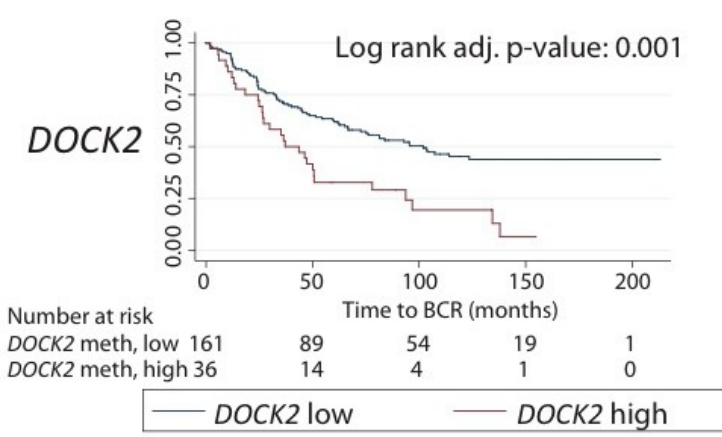

Kaplan-Meier survival estimates

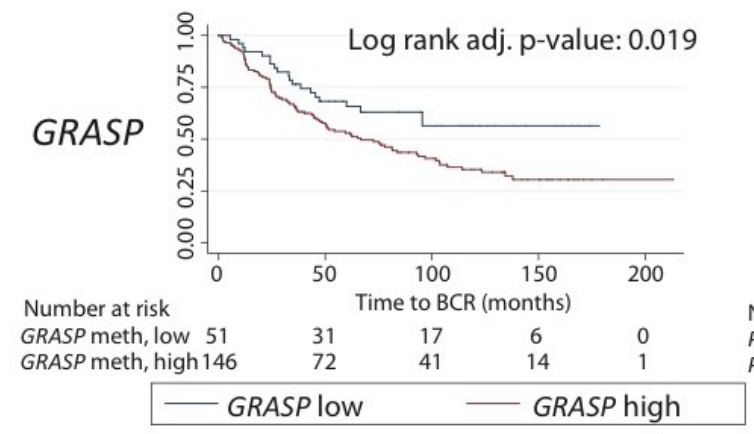

Kaplan-Meier survival estimates

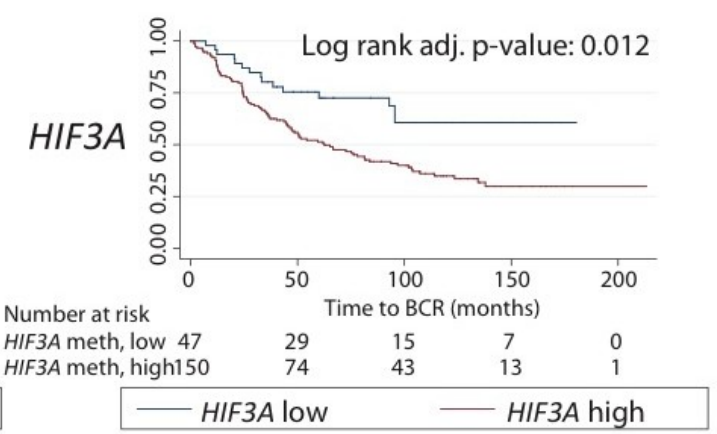

Kaplan-Meier survival estimates

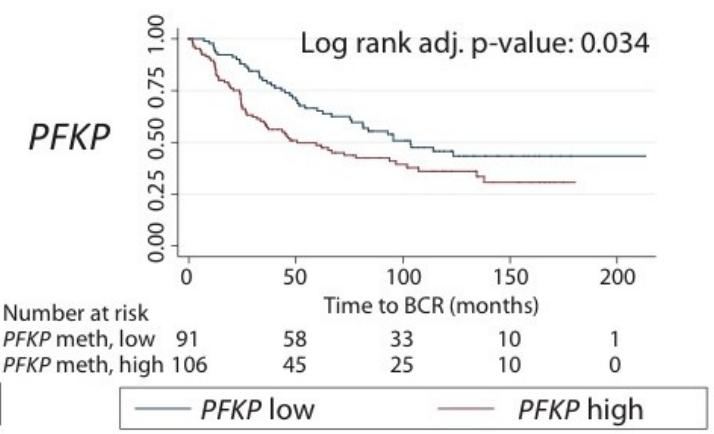

Figure 6. Kaplan-Meier plots with biochemical recurrence (BCR) as an endpoint in the Danish RP cohort. For each marker candidate, the patients were divided into low and high methylation subgroups based on the ROC curve analysis of the BCR status at the 36 months follow-up after RP. $p$-value from the log-rank test.

Finally, for independent clinical validation, we tested the prognostic potential of DOCK2 hypermethylation in another large RP patient set (450K data) available from TCGA. A high DOCK2 methylation level was also a significant adverse predictor of BCR-free survival in this cohort (log-rank $p=0.020$, Figure 7), thereby confirming our own findings in the Danish RP cohort. In summary, this is the first study to demonstrate and externally validate a significant prognostic value for DOCK2 hypermethylation in relation to PCa.

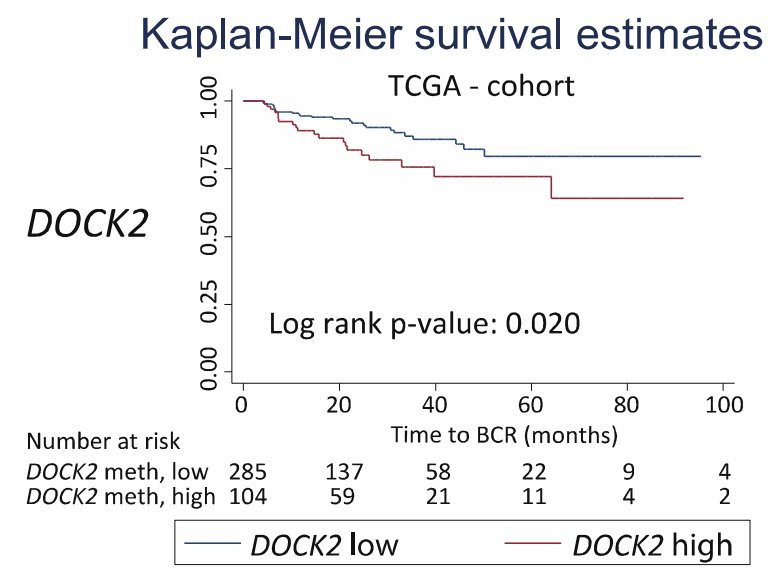

Figure 7. External validation of prognostic potential of DOCK2 hypermethylation in The Cancer Genome Atlas (TCGA) cohort. Kaplan-Meyer plots with biochemical recurrence (BCR) as an endpoint. Division of patients into low and high methylation groups was based on the ROC curve analysis of the BCR status at 36 months after RP. P-value from the log-rank test. 


\subsection{Prognostic Potential of DOCK2 Hypermethylation in the Pre-Operative Setting}

As a proof-of-principle, we assessed the possible prognostic value of DOCK2 hypermethylation as compared to pre-operative clinicopathological factors in our large Danish PCa cohort (Table 1). We found that DOCK2 was a significant independent predictor of time to BCR beyond the pre-operative D'Amico stratification (HR (95\%): 2.26 (1.40-3.63), $p=0.001$, multivariate Cox regression) (Table S5). Moreover, the addition of DOCK2 to the prognostic model increased Harrell's C-index from 0.599 (D'Amico alone) to 0.645 ( $\mathrm{D}^{\prime}$ Amico + DOCK2), suggesting that DOCK2 may improve PCa risk stratification at the time of diagnosis and as a supplement to the $\mathrm{D}^{\prime}$ Amico risk stratification.

To further address this, we tested the prognostic value of DOCK2 hypermethylation within distinct D'Amico risk subgroups (low, intermediate and high). We found no significant added prognostic value for DOCK2 hypermethylation in the low $(n=23)$ and intermediate risk $(n=80)$ patient subgroups (log-rank p: 0.398 and 0.174). In contrast, in the high-risk subgroup $(n=91)$, patients with high DOCK2 methylation showed significantly shorter BCR-free survival than patients with low DOCK2 methylation (29.8 versus 61.9 months median; Kaplan-Meier, log-rank $p<0.001$, Figure 8). Notably, in the currently available follow-up, all patients in this sub-group with high DOCK2 methylation experienced BCR in contrast to only $60 \%$ in the low methylation group (Figure 8), indicating that this very high-risk patient subgroup would be candidates for intensified treatment, for example, adjuvant treatment after RP. Further clinical validation is warranted to assess the possible added value of DOCK2 methylation analyses for PCa risk stratification and to guide more personalized treatment decisions. Information on biopsy GS was not available for the cohort from TCGA, which therefore could not be included in this analysis.

\section{Kaplan-Meier survival estimates High-risk D'Amico}

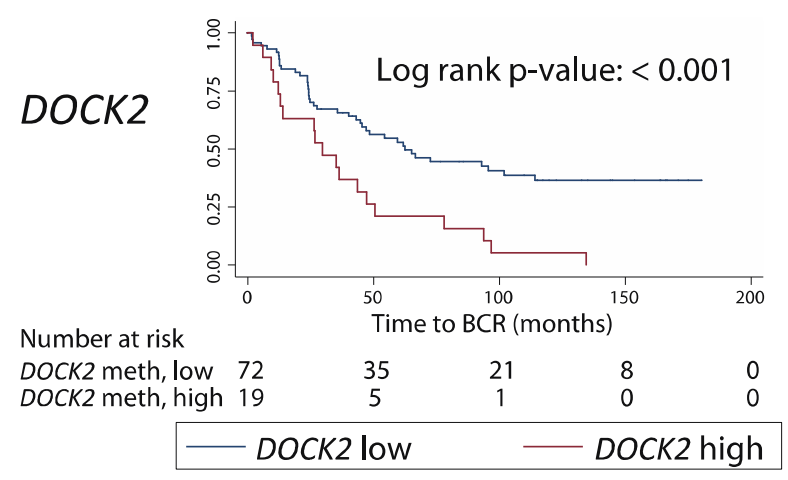

Figure 8. Kaplan-Meier plots with biochemical recurrence (BCR) as an endpoint in the subgroup of Danish PCa patients with D'Amico high-risk. Patients were divided into low and high methylation groups for DOCK2 based on the ROC curve analysis of the BCR status at 36 months post-RP. $p$-value from the log-rank test.

\section{Discussion}

\subsection{Major Findings}

In this study, we used the large Marmal-aid [19] database for the systematic discovery of novel PCa-specific hypermethylation biomarkers that would potentially also be suitable for future transfer into blood-based molecular tests. In summary, we identified and validated eight top candidate markers (DOCK2, FBXO30, HIF3A, GRASP, MOB3B, PFKP, TPM4 and cg12799885) that were significantly hypermethylated in $\mathrm{PCa}$ compared to non-malignant prostate tissue samples, as well as to other cancer types, and which were essentially unmethylated in the $\mathrm{PBC}$ samples, together indicating promising diagnostic potential. Aberrant hypermethylation of DOCK2, HIF3A, GRASP, and PFKP was also a significant adverse predictor of post-operative $B C R$ beyond the routine clinicopathological parameters, 
with DOCK2 being the most promising single candidate prognostic marker. Further validation studies are needed to assess the potential future clinical value of these findings.

\subsection{Diagnostic and Prognostic Potential of Eight Top Candidate Hypermethylation Markers}

To the best of our knowledge, this is the first report to identify DOCK2, FBXO30, PFKP, and $\operatorname{cg} 12799885$ as frequent targets of aberrant hypermethylation in PCa tissue samples. In addition, our results confirm and expand on earlier reports of HIF3A, GRASP, MOB3B and TPM4 hypermethylation in PCa. Specifically, three previous tissue-based studies reported promising diagnostic potential for HIF3A, GRASP, MOB3B and/or TPM4 hypermethylation in PCa with AUCs ranging from 0.93-0.99 [15,21], which is comparable to our current results (AUC range: 0.91-0.95).

Here, we also found that DOCK2, FBXO30, HIF3A, GRASP, MOB3B, PFKP, TPM4 and cg12799885 hypermethylation was undetectable in the PBC samples $(n=896$ samples analyzed in total by $450 \mathrm{~K} /$ Marmal-aid or qMSP), suggesting promising future potential for blood-based testing. Accordingly, future studies should evaluate if these eight top candidate markers can be used for blood-based detection of $\mathrm{PCa}$, thereby helping to reduce the number of unnecessary prostate biopsies.

Our current work is the first to demonstrate the significant prognostic value for DOCK2, HIF3A, GRASP and PFKP hypermethylation in relation to PCa. The most promising single marker in our RP cohort was DOCK2, which remained significant in the multivariate analysis even after adjusting for the other three candidates (see Table S3). This was also successfully validated in the large external RP cohort from TCGA. In contrast, we did not find significant independent prognostic value for FBXO30, MOB3B, TPM4 or cg12788951 hypermethylation in our large RP cohort $(n=197)$. This is consistent with the results from our previous report [15] that also showed no significant associations between MOB3B hypermethylation and BCR in two distinct RP patient cohorts, as well as with another earlier case-control study that found no significant association between TPM4 hypermethylation and PCa-specific death [22]. No previous studies have assessed the prognostic potential of FBXO30 or cg12788951 hypermethylation in relation to PCa.

Further clinical validation studies are warranted in order to investigate if the methylation analyses of DOCK2, FBXO30, PFKP and/or cg12799885 may be used to improve PCa risk stratification at the time of diagnosis. Indeed, from a clinical perspective, it remains a highly complicated task to decide which PCa patients to treat immediately (typically via RP or radiotherapy (RT)) and whom to observe (AS) due to a lack of accurate prognostic tools. The most commonly used nomogram for PCa risk stratification and the guidance of initial treatment decisions is the D'Amico score, but it is suboptimal and leads to both over- and under-treatment. Our current results suggest that the methylation analysis of DOCK2 could potentially be used as an add-on to the D'Amico risk score in order to help improve the accuracy of PCa risk stratification, although further clinical validation in tissue biopsies is required to fully assess this.

Furthermore, in the post-operative setting, several clinical nomograms for determining the risk of recurrence have been developed (e.g., Stephenson, CAPRA-S and Kattan) and can be used to identify high-risk patients eligible for adjuvant treatment and/or intensified follow-up monitoring [23]. Our results suggest that the DOCK2, HIF3A, GRASP and PFKP methylation analyses of RP specimens may be able to assist in the identification of patients at particularly high risk of BCR. Further studies are needed to investigate if the DOCK2, HIF3A, GRASP and/or PFKP methylation analysis of RP specimens may be used to help identify patients who would benefit for adjuvant compared to salvage RT [24], as well as to guiding the optimal timing of initiating androgen deprivation therapy (ADT) after recurrence [25].

\subsection{Known Molecular Functions and Relations to Cancer.}

While cg12799885 is not clearly linked to any annotated human genes, the other seven top candidate genes identified here have all been previously studied in relation to cancer, although their possible functional roles in PCa remain largely unexplored. DOCK2 is an atypical guanine nucleotide 
exchange factor that has been shown to be involved in the regulation of cell migration and proliferation through the small $\mathrm{G}$ protein Rac in various cancer types [26]. One previous study showed that siRNA-based knockdown of DOCK2 in the androgen-resistant PCa cell line PC3 had no effect on cell invasion, but inhibited CXCL13-induced cell proliferation [27]. However, the same study [27] found that the hormone-sensitive PCa cell line LNCaP did not express the DOCK2 protein, together suggesting that the function of DOCK2 in PCa may be cell-state dependent. We did not find DOCK2 expression to be significantly downregulated in PCa tissue samples as compared to adjacent normal prostate tissue samples, potentially suggesting that DOCK2 hypermethylation may not be a driver event in early stage hormone-naïve PCa.

HIF3A belongs to the transcription factor family of hypoxia-inducible factors (HIFs), which regulate the cellular response to hypoxia [28]. While high expression of HIF3A in endometrial cancer has been correlated with poor outcomes, its functional role remains to be elucidated in relation to PCa [28]. GRASP proteins are Golgi-localized homotypic membrane tethers that organize Golgi stacks into long, continuous ribbon-like structures. Although GRASP is known to be hypermethylated in colorectal [29], liver [30], and prostate cancer [21], as also found in the present study, its possible functional role in relation to cancer initiation/progression remains to be examined.

TPM4 belongs to the tropomyosin family of actin-binding proteins, which regulate the contractile system in both muscle and non-muscle cells. Similar to the downregulation of TPM4 gene expression in PCa found in the current study, TPM4 has previously been reported as downregulated in metastatic lung cancer [31,32], but as upregulated in ovarian cancer [33]. Furthermore, in colon cancer, high expression of TPM4 has been correlated with shorter overall survival [34], while we found that TPM4 hypermethylation was linked with transcriptional downregulation, as well as with BCR in $\mathrm{PCa}$, together suggesting a cell type-specific role.

MOB3B belongs to the MOB family of kinase regulators, which are involved in the regulation of cell division (mitotic checkpoint regulation). Here, we found $M O B 3 B$ to be hypermethylated and downregulated in PCa. Similarly, low expression of MOB3B has been associated with malignant melanoma [35], mantle cell lymphoma [35], poor outcome of renal cancer [36] and adverse clinicopathological factors in $\mathrm{PCa}$ [37], together suggesting a possible tumor suppressor role for MOB3B. The FBXO30 protein is involved in protein modifications trough the ubiquitin proteasome pathway [38], but it has not previously been investigated in relation to PCa. Although we found FBXO30 to be significantly downregulated in PCa versus nonmalignant PCa tissue samples in the cohort from TCGA, others have reported FBXO30 as upregulated in PCa and for example in nasopharyngeal cancer [30]. Thus, further studies are needed to investigate the role of FBXO30 in PCa. PFKP is a member of the phosphofructokinase A protein family, which is involved in glycolysis [39]. In this study, the PFKP gene was found to be hypermethylated and downregulated in PCa. This is in agreement with a previous study that also reported PFKP to be downregulated in PCa [40], but in contrast to lung cancer where PFKP has been suggested as an oncogene [41].

In summary, further studies are needed to investigate the possible functional role of DOCK2, FBXO30, HIF3A, GRASP, MOB3B, PFKP and TPM4 in relation to PCa. Future studies are also needed to identify possible candidate genes that could be linked to the hypermethylation of $\operatorname{cg} 12799885$.

\subsection{Study Limitations}

There are some potential limitations to the present study. First, all DNA methylation analyses were limited to tissue samples, although our ultimate future goal is to develop a blood-based DNA methylation test for PCa. Thus, although blood-based analyses are considered to be beyond the scope of the present report, the next future step should be to test our top candidate PCa hypermethylation markers in the analysis of ctDNA in plasma samples. Aberrantly methylated tumor DNA is not necessarily released in sufficient amounts and may not be preserved in plasma, where only nucleosome-associated DNA fragments are protected from DNase activity [42]. Together, these factors may limit sensitivity for PCa detection by ctDNA analysis, but could potentially be mitigated by 
analyzing several DNA methylation candidate markers in parallel and/or very large volumes of plasma. Furthermore, to ensure the high specificity of future ctDNA-based methylation tests, we used a very stringent biomarker discovery approach that should eliminate (or at least minimize the risk of) false positive signals in the plasma from leukocyte-derived genomic DNA, which constitutes the vast majority of cfDNA, particularly in patients with early stage cancer and with relatively low tumor burden [43].

Moreover, the present study was based on available RP specimens and retrospective data collection, which may potentially lead to selection bias. However, our RP cohort used for the qMSP analyses seemed to be representative, as all of the routine clinicopathological factors (preoperative PSA, pT-stage, pGS, SM status) were significant predictors of BCR in the univariate analyses. Furthermore, we also successfully validated the prognostic potential of our top candidate prognostic marker DOCK2 in the large external RP patient cohort available from TCGA.

Another potential limitation is the use of BCR as the clinical endpoint, since not at all RP patients with BCR will eventually develop metastatic disease or die from PCa in their lifespan [44]. We did not have a sufficient number of events to analyze these additional clinical endpoints in our RP patient cohort, nor in the external validation cohort from TCGA. Thus, further studies are needed to determine the true clinical value of DOCK2, HIF3A, GRASP and/or PFKP methylation levels for the prediction of metastatic progression and PCa-specific survival. However, given the slow progressing nature of early stage $\mathrm{PCa}$, such future studies would require $>10$ years of clinical follow-up [45].

\section{Materials and Methods}

\subsection{Biomarker Discovery}

The methylome data (B-value, disease status and gender) was downloaded from the Marmal-aid database [19], which contains genome-wide methylome data (Illumina InfiniumHumanMethylation450 (450K) array) from $>14,000$ tissue samples of various organ/cell types. The data were adjusted for intrasample variation by beta-mixture quantile (BMIQ) normalization, using the ChAMP package (version 1.8.0) for R prior to further analysis [46]. In the bioinformatic analysis, we initially excluded CpG sites that displayed signs of even low DNA methylation levels (ß-value $>0.2$ ) in more than $1 \%$ of blood specimens to find potential biomarkers suitable for future blood-based tests. We then used a two-stringed approach to find CPG sites that had a different methylation pattern in PCa compared to normal prostate tissue samples. For search string 1 ("pan-cancer" biomarker candidates), we selected CpG sites displaying hypermethylation (B-value $>0.5$ ) in more than $80 \%$ of PCa tissue samples and excluded CpG sites with a methylation level where the $B$-value was $>0.2$ in more than $19 \%$ of normal prostate tissue samples. In search string 2 (PCa-specific biomarker candidates), we selected CpG sites displaying hypermethylation ( $($-value $>0.5$ ) in more than $60 \%$ of PCa tissue samples and excluded CpG sites which were hypermethylated ( $B$-value $>0.2)$ in more than $8 \%$ of tissue samples from other cancer types as well as CpG sites, where there was a detectable methylation level ( $($-value $>0.2$ ) in more than $30 \%$ of normal prostate tissue samples.

For each top candidate gene identified, methylation-specific assays for qPCR analysis were designed using Beacon Designer ${ }^{\mathrm{TM}}$ (Premier Biosoft, Palo Alto, CA, USA; Table S6). As reference genes for DNA quantification and quality control, ALUC4 and MYOD1 were used [14,15]. Locked nucleic acid $\left(\mathrm{LMA}^{\mathrm{TM}}\right.$ )-based qMSP assays were designed by Exiqon-a Quiagen company (Vedbæk, Denmark). During the assay design, the LNA ${ }^{\mathrm{TM}}$ Oligo Optimizer tool (found at https:/ / www.exiqon. com/ls/Pages/ExiqonOligoOptimizerTool.aspx) was used to ensure LNA ${ }^{\mathrm{TM}}$ oligo designs with a self-complementarity and secondary structure score below 40 . The annealing temperatures $(\mathrm{Tm})$ of the LNA ${ }^{\mathrm{TM}}-$-enhanced oligos were predicted using the LNA ${ }^{\mathrm{TM}}$ Oligo Tm Prediction tool (found at https://www.exiqon.com/ls/Pages/ExiqonTMPredictionTool.aspx). The primers were designed to have a $\mathrm{Tm}=59-61{ }^{\circ} \mathrm{C}$ and a probe $\mathrm{Tm}=$ primer $\mathrm{Tm}+5-10{ }^{\circ} \mathrm{C}$. The primers were purchased from 
Integrated DNA Technologies (Leuven, Belgium) and the Taqman ${ }^{\circledR}$ probes were ordered from LGC Biosearch Technologies (Risskov, Denmark).

\subsection{Patients and Tissue Samples}

All patients provided written informed consent prior to inclusion in the study and the study was approved by The Committee on Health Research Ethics for the Central Denmark Region (No. 2000/0299, 28 March 2017) and The Danish Data Protection Agency (No. 2013-41-2041, 27 January 2016).

\subsubsection{Patient Samples for Small-Scale Experimental Validation}

Twenty PCa tissue samples (RP specimens from patients without BCR), 20 BPH/AN, 20 whole-blood samples from PCa patients and 20 buffycoat samples (i.e., mainly leukocytes) from healthy male blood donors were used for experimental validation of the top candidate markers identified from the analysis of the Marmal-aid dataset. All tissue samples were collected at Aarhus University Hospital, Denmark. Five samples (4 PCa and 1 AN) failed the quality control (less than two out of three replicates with detectable levels of the reference genes ALUC4 and MYOD1) and hence were not included in the final analyses [14,15].

\subsubsection{Clinical Cohort for Large-Scale Validation}

Patients with histologically confirmed clinically localized PCa that were treated by curatively intended RP at Aarhus University Hospital from 1999-2013 were used for large-scale validation. The inclusion criteria were as follows: Available formalin-fixed paraffin embedded (FFPE) tissue (PCa and/or AN) which had been subjected to histological verification by an expert uropathologist, and good DNA quality (minimum DNA concentration of $100 \mathrm{ng} / \mathrm{ul}$ after DNA purification). A total of 264 PCa patients (254 PCa tissue and 37 AN tissue samples and 27 patients with matched PCa and AN tissue samples) were included in this phase of the study. As additional non-cancer controls, tissue samples from nine patients with $\mathrm{BPH}$, who underwent transurethral resection of the prostate (TURP) were also included. A total of $55 \mathrm{PCa}$ and $9 \mathrm{AN}$ samples did not pass the final quality control during qMSP (less than two out of three replicates with detectable levels of the reference genes ALUC4 and MYOD1), thus, the final cohort consisted of $197 \mathrm{PCa}$ and 37 non-malignant prostate tissue samples (28 AN and $9 \mathrm{BPH}$ ). See Table 1 for an overview of the clinicopathological characteristics.

\subsection{DNA Extraction, Bisulfite Conversion and Quantitative Methylation-Specific PCR Analysis (qMSP)}

Genomic DNA was extracted from FFPE punch biopsies from the RP specimens (PCa and AN) or TURP specimens (BPH), as previously described [14-16]. Genomic DNA from blood cells was extracted from whole blood and / or buffycoat from healthy blood donors using the QIASymphony DSP DNA Midi Kit (Qiagen, Hilden, Germany, Cat\#937255).

The EZ Methylation-Direct Kit (Zymo Research, Irvine, CA, USA) was used for bisulfite conversion of $1000 \mathrm{ng}$ of DNA input from each sample. Next, quantitative methylation-specific PCR (qMSP) analyses were run, as previously described $[14,15]$. In brief, all reactions were run in triplicates with $5 \mathrm{ng}$ bisulfite converted DNA as the input, using the Taqman universal mastermix (no UNG) on the Thermofisher ViiA ${ }^{\mathrm{TM}} 7$ real-time PCR system. Each 384-well plate included serially diluted methylated DNA samples for standard curve analyses, fully-methylated positive control (bisulfite converted CpGenome Universal Methylated DNA; Merck/Millipore), fully unmethylated negative control (whole-genome amplified DNA (WGA), and a no-template control (water). As reference genes for DNA quantification and quality control, ALUC4 and MYOD1 were used, and the data were normalized to ALUC4 as previously described [14,15]. The quantity was arbitrarily set to 0 for patient samples with a $C_{T}$ value $>40$ (undetermined) and/or a $C_{T}$ value above the $C_{T}$ value for the negative controls (WGA and water) in the same qMSP run, except in the small-scale experimental validation, where the quantity was set to 0 for all patient samples with a $C_{T}$ value $>37$. The quality control steps 
for all runs encompassed the exclusion of samples with a quantification cycle $\left(\mathrm{C}_{\mathrm{T}}\right)>24$ for ALUC4, and/or without a MYOD1 positive signal and/or samples with $<2$ of the triplicate reactions amplified (after the removal of outliers $>2 C_{T}$ s lower/higher, compared to other $C_{T} s$ in triplicate).

\subsection{TCGA Data Used for External Validation of DOCK2 Prognostic Potential}

The DNA methylome data (450K array data), RNA sequencing data and clinical data for PCa tissue samples from $498 \mathrm{RP}$ patients and 52 matched AN samples was downloaded from the TCGA platform [42] and used for external validation.

\subsection{Statistical Analyses}

STATA v.15 (StataCorp, Collage Station, TX, USA) and R version 3.5.0 were used for the statistical analyses [47].

Statistical significance was set at $p<0.05$. When appropriate, the Benjamini-Hochberg method [48] was used to correct for multiple testing. The diagnostic value was assessed using the Wilcoxon Mann-Whitney test and ROC curve analyses of the methylation levels in malignant (PCa) versus non-malignant $(\mathrm{AN} / \mathrm{BPH})$ specimens. The prognostic potential of the methylation biomarker candidates was evaluated using uni- and multivariate Cox regression analyses, Kaplan-Meier analysis and two-sided log-rank tests. For the Kaplan-Meier analyses and log-rank tests, the patients were divided into high- and low-methylation groups based on cutoffs from the ROC analyses (BCR status at 36 months follow-up) for each candidate marker. Post-operative BCR (defined as PSA $\geq 0.2 \mathrm{ng} / \mathrm{mL}$ ) was the clinical endpoint for all prognostic analyses. Lymph node status was not included in the multivariate analyses as very few patients (2.5\%) were lymph node positive. Harrell's C-index [49] was used to estimate predictive accuracy.

\section{Conclusions}

In this study, we identified and validated DOCK2, FBXO30, HIF3A, GRASP, MOB3B, PFKP, TPM4 and cg12799885 as novel PCa-specific hypermethylation candidate markers. Our results also suggest promising potential for all of these candidate markers in future blood-based testing, as none of them had detectable DNA methylation levels in PBC samples. Four of the top candidate markers (DOCK2, GRASP, HIF3A and PKFP) showed prognostic potential for the prediction of BCR after RP, with the most promising single candidate marker being DOCK2. Indeed, we identified DOCK2 hypermethylation as a novel independent predictor of post-operative BCR beyond routine clinicopathological parameters (pre-operative as well as post-operative) and successfully validated this in a large independent RP cohort which was available from TCGA. Further studies are warranted to assess the possible future clinical utility of this novel set of epigenetic diagnostic and prognostic biomarker candidates for PCa.

Supplementary Materials: Supplementary materials can be found at http:/ / www.mdpi.com/1422-0067/20/5/ 1173 /s1. Figure S1. Cancer type related methylation levels (ß-value) of the 11 selected biomarker candidates. Figure S2. Methylation level of biomarker candidates in AN/BPH and PCa tissue samples-small scale validation. Figure S3. Methylation levels of biomarker candidates in AN/BPH and PCa tissue samples-large scale validation. Figure S4. Correlation between RNA expression and DNA methylation for the biomarker candidates-validation in the cohort from TCGA. Table S1. Marmal-aid dataset (450K array data). Table S2. Small scale validation. Table S3. Large scale validation. Table S4. Stepwise backward selection multivariate Cox regression analyses of BCR-free survival after RP. Table S5. Multivariate Cox regression analysis of BCR-free survival in relation to the known preoperative D'Amico risk classification. Table S6. Primer and probe sequences for the qMSP assays used for small scale validation.

Author Contributions: Conceptualization: M.T.B., S.H.S. and K.D.S.; Data curation: M.T.B., B.U. and J.F.; Formal analysis: M.T.B., S.H.S., M.N. and M.M.M.; Funding acquisition: K.D.S., T.Ø., P.M., M.T.B.; Methodology: M.T.B., S.H.S., H.K., A.K.R. and J.F.; Resources: M.B. and B.U.; Supervision: P.M., T.Ø., M.B. and K.D.S.; Visualization: M.T.B.; Writing—original draft, M.T.B., S.H.S. and K.D.S.; Writing—review and editing: All authors. 
Funding: This research was founded by The Danish Cancer Society (R99-A6338-14-S25), The Velux Foundation (11307), Innovation Fund Denmark (068-2012-3) and The Danish Cancer Foundation (Dansk Kræftforskningsfond).

Acknowledgments: The authors thank Birgitte Trolle, Pamela Celis, Margaret Gellet, Mie Aarup and Jesper Boulund Kristensen for their excellent technical assistance and Sara Østrup Jensen, Trine Mattesen, Jesper Bramsen and Ole Halfdan for their helpful discussions. The results published here are in part based upon data generated by the TCGA Research Network (https://cancergenome.nih.gov/) as well as the Marmal-aid dataset: http:/ / marmal-aid.org. The Danish Cancer Biobank is acknowledged for providing patient samples and information on handling and storage.

Conflicts of Interest: K.D.S. and T.Ø. are co-inventors on patent applications for DNA methylation markers for prostate cancer. K.D.S. has received consultancy fees from Exiqon.

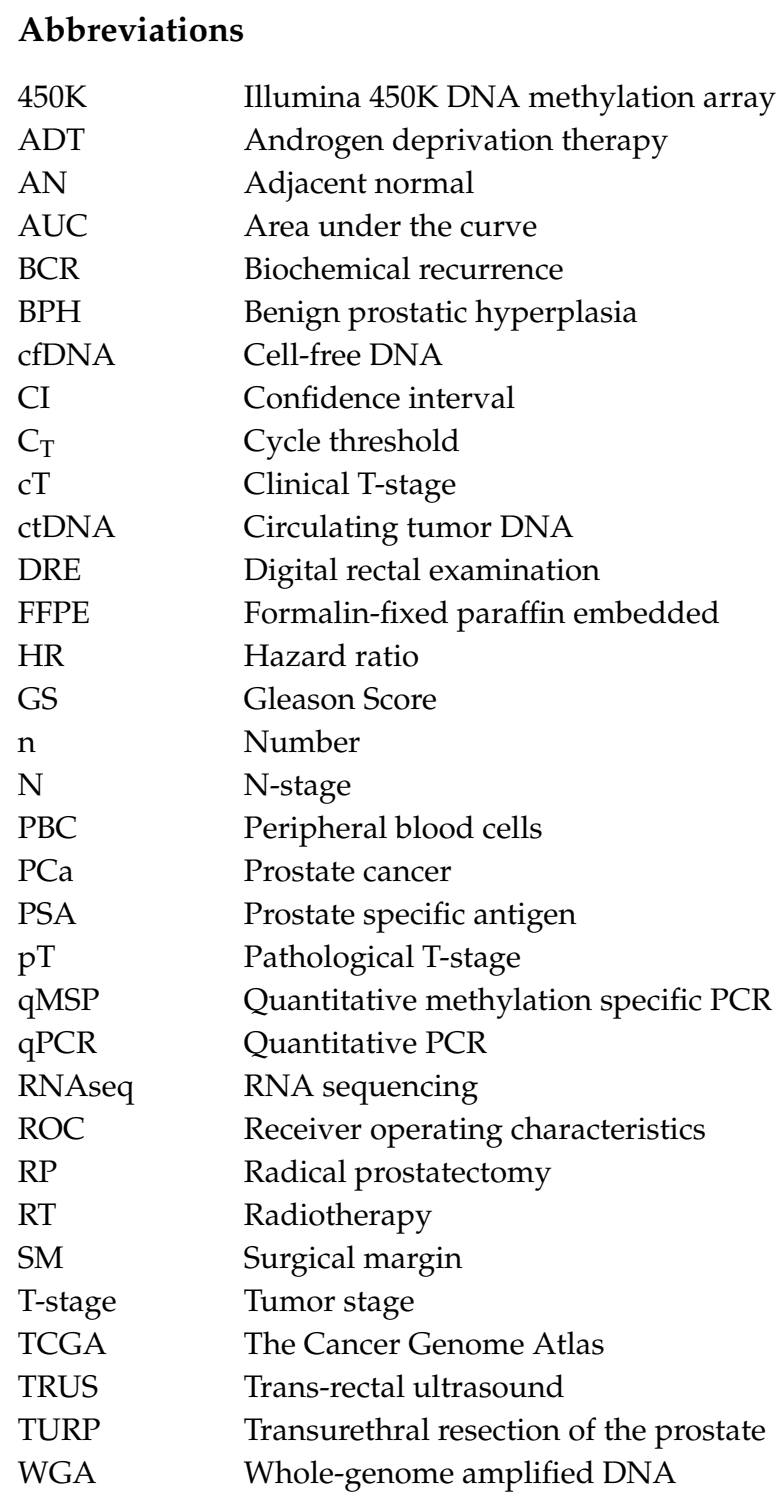

\section{References}

1. Ferlay, J.; Soerjomataram, I.; Dikshit, R.; Eser, S.; Mathers, C.; Rebelo, M.; Parkin, D.M.; Forman, D.; Bray, F. Cancer incidence and mortality worldwide: Sources, methods and major patterns in GLOBOCAN 2012. Int. J. Cancer 2015, 136, E359-E386. [CrossRef] [PubMed]

2. Ferlay, J.; Steliarova-Foucher, E.; Lortet-Tieulent, J.; Rosso, S.; Coebergh, J.W.; Comber, H.; Forman, D.; Bray, F. Cancer incidence and mortality patterns in Europe: Estimates for 40 countries in 2012. Eur. J. Cancer 2013, 49, 1374-1403. [CrossRef] [PubMed] 
3. Mottet, N.; Bellmunt, J.; Bolla, M.; Briers, E.; Cumberbatch, M.G.; De Santis, M.; Fossati, N.; Gross, T.; Henry, A.M.; Joniau, S.; et al. EAU-ESTRO-SIOG guidelines on prostate cancer. Part 1: Screening, diagnosis, and local treatment with curative intent. Eur. Urol. 2017, 71, 618-629. [CrossRef] [PubMed]

4. Barry, M.J. Clinical practice. Prostate-specific-antigen testing for early diagnosis of prostate cancer. N. Engl. J. Med. 2001, 344, 1373-1377. [CrossRef] [PubMed]

5. Zhang, K.; Bangma, C.H.; Venderbos, L.D.F.; Roobol, M.J. Individual and Population-Based screening. In Management of Prostate Cancer a Multidisciplinary Approach, 2nd ed.; Bolla, M., Van Poppel, H., Eds.; Springer: Basel, Switzerland, 2017; pp. 43-55.

6. Pettersson, A.; Gerke, T.; Fall, K.; Pawitan, Y.; Holmberg, L.; Giovannucci, E.L.; Kantoff, P.W.; Adami, H.O.; Rider, J.R.; Mucci, L.A.; et al. The ABC model of prostate cancer: A conceptual framework for the design and interpretation of prognostic studies. Cancer 2017, 123, 1490-1496. [CrossRef] [PubMed]

7. Thomsen, F.B.; Brasso, K.; Klotz, L.H.; Roder, M.A.; Berg, K.D.; Iversen, P. Active surveillance for clinically localized prostate cancer-A systematic review. J. Surg. Oncol. 2014, 109, 830-835. [CrossRef] [PubMed]

8. D'Amico, A.V.; Whittington, R.; Malkowicz, S.B.; Schultz, D.; Blank, K.; Broderick, G.A.; Tomaszewski, J.E.; Renshaw, A.A.; Kaplan, I.; Beard, C.J.; et al. Biochemical outcome after radical prostatectomy, external beam radiation therapy, or interstitial radiation therapy for clinically localized prostate cancer. JAMA 1998, 280, 969-974. [CrossRef] [PubMed]

9. Gandaglia, G.; Ploussard, G.; Isbarn, H.; Suardi, N.; De Visschere, P.J.; Futterer, J.J.; Ghadjar, P.; Massard, C.; Ost, P.; Sooriakumaran, P.; et al. What is the optimal definition of misclassification in patients with very low-risk prostate cancer eligible for active surveillance? Results from a multi-institutional series. Urol. Oncol. 2015, 33, 164.e1-164.e9. [CrossRef] [PubMed]

10. Cooperberg, M.R.; Broering, J.M.; Carroll, P.R. Time trends and local variation in primary treatment of localized prostate cancer. J. Clin. Oncol. 2010, 28, 1117-1123. [CrossRef] [PubMed]

11. Chalmers, Z.R.; Connelly, C.F.; Fabrizio, D.; Gay, L.; Ali, S.M.; Ennis, R.; Schrock, A.; Campbell, B.; Shlien, A.; Chmielecki, J.; et al. Analysis of 100,000 human cancer genomes reveals the landscape of tumor mutational burden. Genome Med. 2017, 9, 34. [CrossRef] [PubMed]

12. Baylin, S.B.; Esteller, M.; Rountree, M.R.; Bachman, K.E.; Schuebel, K.; Herman, J.G. Aberrant patterns of DNA methylation, chromatin formation and gene expression in cancer. Hum. Mol. Genet. 2001, 10, 687-692. [CrossRef] [PubMed]

13. Esteller, M. Cancer epigenomics: DNA methylomes and histone-modification maps. Nat. Rev. Genet. 2007, 8, 286-298. [CrossRef] [PubMed]

14. Strand, S.H.; Switnicki, M.; Moller, M.; Haldrup, C.; Storebjerg, T.M.; Hedegaard, J.; Nordentoft, I.; Hoyer, S.; Borre, M.; Pedersen, J.S.; et al. RHCG and TCAF1 promoter hypermethylation predicts biochemical recurrence in prostate cancer patients treated by radical prostatectomy. Oncotarget 2017, 8, 5774-5788. [CrossRef] [PubMed]

15. Haldrup, C.; Mundbjerg, K.; Vestergaard, E.M.; Lamy, P.; Wild, P.; Schulz, W.A.; Arsov, C.; Visakorpi, T.; Borre, M.; Hoyer, S.; et al. DNA methylation signatures for prediction of biochemical recurrence after radical prostatectomy of clinically localized prostate cancer. J. Clin. Oncol 2013, 31, 3250-3258. [CrossRef] [PubMed]

16. Kristensen, H.; Haldrup, C.; Strand, S.; Mundbjerg, K.; Mortensen, M.M.; Thorsen, K.; Ostenfeld, M.S.; Wild, P.J.; Arsov, C.; Goering, W.; et al. Hypermethylation of the GABRE miR-452 miR-224 promoter in prostate cancer predicts biochemical recurrence after radical prostatectomy. Clin. Cancer Res. 2014, 20, 2169-2181. [CrossRef] [PubMed]

17. Strand, S.H.; Orntoft, T.F.; Sorensen, K.D. Prognostic DNA methylation markers for prostate cancer. Int J. Mol. Sci. 2014, 15, 16544-16576. [CrossRef] [PubMed]

18. Hoque, M.O. DNA methylation changes in prostate cancer: Current developments and future clinical implementation. Expert Rev. Mol. Diagn 2009, 9, 243-257. [CrossRef] [PubMed]

19. Lowe, R.; Rakyan, V.K. Marmal-aid-a database for Infinium HumanMethylation450. BMC Bioinformatics 2013, 14, 359. [CrossRef] [PubMed]

20. Cooperberg, M.R.; Hilton, J.F.; Carroll, P.R. The CAPRA-S score: A straightforward tool for improved prediction of outcomes after radical prostatectomy. Cancer 2011, 117, 5039-5046. [CrossRef] [PubMed]

21. Mahapatra, S.; Klee, E.W.; Young, C.Y.; Sun, Z.; Jimenez, R.E.; Klee, G.G.; Tindall, D.J.; Donkena, K.V. Global methylation profiling for risk prediction of prostate cancer. Clin. Cancer Res. 2012, 18, 2882-2895. [CrossRef] [PubMed] 
22. Vasiljevic, N.; Ahmad, A.S.; Carter, P.D.; Fisher, G.; Berney, D.M.; Foster, C.S.; Cuzick, J.; Lorincz, A.T. DNA methylation of PITX2 predicts poor survival in men with prostate cancer. Biomark. Med. 2014, 8, 1143-1150. [CrossRef] [PubMed]

23. Campbell, J.M.; Raymond, E.; O'Callaghan, M.E.; Vincent, A.D.; Beckmann, K.R.; Roder, D.; Evans, S.; McNeil, J.; Millar, J.; Zalcberg, J.; et al. Optimum Tools for Predicting Clinical Outcomes in Prostate Cancer Patients Undergoing Radical Prostatectomy: A Systematic Review of Prognostic Accuracy and Validity. Clin. Genitourin. Cancer 2017, 15, e827-e834. [CrossRef] [PubMed]

24. Briganti, A.; Wiegel, T.; Joniau, S.; Cozzarini, C.; Bianchi, M.; Sun, M.; Tombal, B.; Haustermans, K.; Budiharto, T.; Hinkelbein, W.; et al. Early salvage radiation therapy does not compromise cancer control in patients with $\mathrm{PT} 3 \mathrm{~N} 0$ prostate cancer after radical prostatectomy: Results of a match-controlled multi-institutional analysis. Eur. Urol. 2012, 62, 472-487. [CrossRef] [PubMed]

25. Ravi, P.; Karnes, R.J.; Rangel, L.J.; Pagliaro, L.C. Outcomes and Prognostic Factors in Men Receiving Androgen Deprivation Therapy for Prostate Cancer Recurrence after Radical Prostatectomy. J. Urol. 2018. [CrossRef] [PubMed]

26. Chen, Y.; Meng, F.; Wang, B.; He, L.; Liu, Y.; Liu, Z. Dock2 in the development of inflammation and cancer. Eur. J. Immunol. 2018, 48, 915-922. [CrossRef] [PubMed]

27. El-Haibi, C.P.; Singh, R.; Sharma, P.K.; Singh, S.; Lillard, J.W., Jr. CXCL13 mediates prostate cancer cell proliferation through JNK signalling and invasion through ERK activation. Cell Prolif. 2011, 44, 311-319. [CrossRef] [PubMed]

28. Uhlen, M.; Zhang, C.; Lee, S.; Sjostedt, E.; Fagerberg, L.; Bidkhori, G.; Benfeitas, R.; Arif, M.; Liu, Z.; Edfors, F.; et al. A pathology atlas of the human cancer transcriptome. Science 2017, 357. [CrossRef] [PubMed]

29. Mitchell, S.M.; Ross, J.P.; Drew, H.R.; Ho, T.; Brown, G.S.; Saunders, N.F.; Duesing, K.R.; Buckley, M.J.; Dunne, R.; Beetson, I.; et al. A panel of genes methylated with high frequency in colorectal cancer. BMC Cancer 2014, 14, 54. [CrossRef] [PubMed]

30. Yamada, N.; Yasui, K.; Dohi, O.; Gen, Y.; Tomie, A.; Kitaichi, T.; Iwai, N.; Mitsuyoshi, H.; Sumida, Y.; Moriguchi, M.; et al. Genome-wide DNA methylation analysis in hepatocellular carcinoma. Oncol. Rep. 2016, 35, 2228-2236. [CrossRef] [PubMed]

31. Kopantzev, E.P.; Monastyrskaya, G.S.; Vinogradova, T.V.; Zinovyeva, M.V.; Kostina, M.B.; Filyukova, O.B.; Tonevitsky, A.G.; Sukhikh, G.T.; Sverdlov, E.D. Differences in gene expression levels between early and later stages of human lung development are opposite to those between normal lung tissue and non-small lung cell carcinoma. Lung Cancer 2008, 62, 23-34. [CrossRef] [PubMed]

32. Rostila, A.; Puustinen, A.; Toljamo, T.; Vuopala, K.; Lindstrom, I.; Nyman, T.A.; Oksa, P.; Vehmas, T.; Anttila, S.L. Peroxiredoxins and tropomyosins as plasma biomarkers for lung cancer and asbestos exposure. Lung Cancer 2012, 77, 450-459. [CrossRef] [PubMed]

33. Tang, H.Y.; Beer, L.A.; Tanyi, J.L.; Zhang, R.; Liu, Q.; Speicher, D.W. Protein isoform-specific validation defines multiple chloride intracellular channel and tropomyosin isoforms as serological biomarkers of ovarian cancer. J. Proteomics 2013, 89, 165-178. [CrossRef] [PubMed]

34. Yang, R.; Zheng, G.; Ren, D.; Chen, C.; Zeng, C.; Lu, W.; Li, H. The clinical significance and biological function of tropomyosin 4 in colon cancer. Biomed. Pharmacother. 2018, 101, 1-7. [CrossRef] [PubMed]

35. Thang, N.D.; Yajima, I.; Nakagawa, K.; Tsuzuki, T.; Kumasaka, M.Y.; Ohgami, N.; Ly, T.B.; Iwamoto, T.; Watanabe, D.; Kato, M. A novel hairless mouse model for malignant melanoma. J. Dermatol. Sci. 2012, 65, 207-212. [CrossRef] [PubMed]

36. Uhlen, M.; Fagerberg, L.; Hallstrom, B.M.; Lindskog, C.; Oksvold, P.; Mardinoglu, A.; Sivertsson, A.; Kampf, C.; Sjostedt, E.; Asplund, A.; et al. Proteomics. Tissue-based map of the human proteome. Science 2015, 347, 1260419. [CrossRef] [PubMed]

37. Kim, E.A.; Kim, Y.H.; Kang, H.W.; Yoon, H.Y.; Kim, W.T.; Kim, Y.J.; Yun, S.J.; Moon, S.K.; Choi, Y.H.; Kim, I.Y.; et al. Lower Levels of Human MOB3B Are Associated with Prostate Cancer Susceptibility and Aggressive Clinicopathological Characteristics. J. Korean Med. Sci. 2015, 30, 937-942. [CrossRef] [PubMed]

38. Gene Cards-Human Gene Database. Available online: https://www.genecards.org/cgi-bin/carddisp.pl? gene $=\mathrm{FBXO} 30$ (accessed on 3 September 2018).

39. Lee, J.H.; Liu, R.; Li, J.; Zhang, C.; Wang, Y.; Cai, Q.; Qian, X.; Xia, Y.; Zheng, Y.; Piao, Y.; et al. Stabilization of phosphofructokinase 1 platelet isoform by AKT promotes tumorigenesis. Nat. Commun. 2017, 8, 949. [CrossRef] [PubMed] 
40. Sun, Y.; Jia, X.; Hou, L.; Liu, X. Screening of Differently Expressed miRNA and mRNA in Prostate Cancer by Integrated Analysis of Transcription Data. Urology 2016, 94, 313.e1-313.e6. [CrossRef] [PubMed]

41. Wang, Y.; Mei, Q.; Ai, Y.Q.; Li, R.Q.; Chang, L.; Li, Y.F.; Xia, Y.X.; Li, W.H.; Chen, Y. Identification of lung cancer oncogenes based on the mRNA expression and single nucleotide polymorphism profile data. Neoplasma 2015, 62, 966-973. [CrossRef] [PubMed]

42. The Cancer Genome Atlas. Available online: https:// cancergenome.nih.gov/ (accessed on 1 June 2018).

43. Snyder, M.W.; Kircher, M.; Hill, A.J.; Daza, R.M.; Shendure, J. Cell-free DNA Comprises an In Vivo Nucleosome Footprint that Informs Its Tissues-Of-Origin. Cell 2016, 164, 57-68. [CrossRef] [PubMed]

44. Pound, C.R.; Partin, A.W.; Eisenberger, M.A.; Chan, D.W.; Pearson, J.D.; Walsh, P.C. Natural history of progression after PSA elevation following radical prostatectomy. JAMA 1999, 281, 1591-1597. [CrossRef] [PubMed]

45. Albertsen, P.C. Observational studies and the natural history of screen-detected prostate cancer. Curr. Opin. Urol. 2015, 25, 232-237. [CrossRef] [PubMed]

46. Tian, Y. Chip Analysis Methylation Pipeline for Illumina HumanMethylation450. Available online: https: / / git.bioconductor.org/packages/ChAMP (accessed on 16 September 2015).

47. Team, R.C. R: A Language and Environment for Statistical Computing. Available online: https://www.Rproject.org/ (accessed on 15 April 2018).

48. Hochberg, Y.; Benjamini, Y. More powerful procedures for multiple significance testing. Stat. Med. 1990, 9, 811-818. [CrossRef] [PubMed]

49. Harrell, F.E., Jr.; Lee, K.L.; Mark, D.B. Multivariable prognostic models: Issues in developing models, evaluating assumptions and adequacy, and measuring and reducing errors. Stat. Med. 1996, 15, 361-387. [CrossRef]

(C) 2019 by the authors. Licensee MDPI, Basel, Switzerland. This article is an open access article distributed under the terms and conditions of the Creative Commons Attribution (CC BY) license (http://creativecommons.org/licenses/by/4.0/). 